\title{
Why Do We Procrastinate? Present Bias and Optimism
}

\author{
Zachary Breig, Matthew Gibson, and Jeffrey Shrader*
}

February 15, 2019

\begin{abstract}
A large body of research has shown that procrastination can have significant adverse effects on individuals, including lower savings and poorer health. Such procrastination is typically modeled as the result of present bias. In this paper we study an alternative: excessively optimistic beliefs about future demands on an individual's time. Our experimental results refute the hypothesis that present bias is the sole source of dynamic inconsistency, but they are consistent with optimism. These findings offer an explanation for low takeup of commitment and suggest that personalized information on past choices can mitigate procrastination. (JEL: D90,D84,D15,J22)
\end{abstract}

*Affiliations. Breig: School of Economics, The University of Queensland, Level 6 Colin Clark Building (39), St Lucia, Brisbane, Australia, 4072 (e-mail: z.breig@uq.edu.au); Gibson: Department of Economics, Williams College, 24 Hopkins Hall Drive, Williamstown MA 01267 (e-mail: mg17@williams.edu); Shrader: School of International and Public Affairs, Columbia University, 420 West 118th Street, New York NY 10027 (e-mail: jgs2103@columbia.edu). We are grateful for helpful comments from James Andreoni, Gordon Dahl, Marco Faravelli, Osea Giuntella, Jeff Kline, Bentley MacLeod, Frank Schilbach, Charles Sprenger, and Jack Willis as well as seminar participants at ASHEcon, UCSD, University of Melbourne, and University of Queensland. 


\section{Introduction}

Procrastination is an important feature of everyday life. It is a common topic of conversation at work and at home. Economists have documented it in consequential settings from retirement saving (Thaler and Benartzi, 2004) to exercise (DellaVigna and Malmendier, 2006). Dynamically inconsistent procrastination is commonly modeled as originating from preferences that favor the present at the expense of the future (Strotz, 1955, Laibson, 1997, O’Donoghue and Rabin, 1999, Barro, 1999, Ashraf et al., 2006, Augenblick et al., 2015). ${ }^{1}$ We study an alternative model in which dynamic inconsistency arises from excessive optimism about future demands on an individual's time. While both models predict dynamically inconsistent choices, they predict different responses to information about past procrastination. We test these predictions experimentally, and we reject the hypothesis that present bias is the sole source of dynamic inconsistency. Instead we find evidence that both the discount rate and beliefs matter. Our results suggest that the typical policy prescription-offering people the chance to tie themselves to the mast, committing to decisions in advance - is incomplete, and that personalized historical information is an important additional tool for people making decisions over time.

Biased beliefs about future time shocks can cause choices made ahead of time to differ from choices made in the moment. Consider an agent who does not accurately anticipate the arrival of a time-consuming task. Colloquially we say that such an agent is "optimistic" about her time shocks. Once the task arrives, the agent will need to put off planned time use to accommodate the unanticipated shock. If the agent has systematically biased beliefs over future time shocks, then such procrastination can occur even with neoclassical discounting. We refer to this as belief-based dynamic inconsistency. ${ }^{2}$

Discounting-based dynamic inconsistency, in contrast, models dynamically inconsistent choices as originating from a utility function that places lower weight on the more distant future relative to the immediate future. If an agent is naïve about her own present-biased discounting, she believes that she will behave more consistently

\footnotetext{
${ }^{1}$ In the quasi-hyperbolic model of Laibson (1997), the agent discounts at rate $\delta$ between future periods, but between the current period and the next period at rate $\beta \delta$ with $\beta<1$. This heavier discounting leads to "present biased" allocative choices.

${ }^{2}$ In contrast to Halevy (2008) and Andreoni and Sprenger (2012b), this inconsistency is a result of the decision maker having incorrect beliefs rather than a utility function which does not take the expected utility form.
} 
than she actually does. ${ }^{3}$ This leads the agent to exhibit present-biased dynamic inconsistency because choices made far enough in advance will be governed by geometric discounting while choices made about the immediate future will not.

Because these two models lead to similar dynamically inconsistent choices, a research design seeking to distinguish discounting-based from belief-based dynamic inconsistency cannot rely solely on revealed procrastination. ${ }^{4}$ Providing agents with information on past time-inconsistent decisions resolves this difficulty. Discountingand belief-based models make different predictions about how agents will update their beliefs and respond to information about their own past procrastination behavior.

First, the two models give different predictions for how effort allocation will change in response to information. Discounting-based dynamically inconsistent agents have a clear idea of the time shocks that they face, but have trouble committing to time use choices. Such agents will not change allocation decisions in response to information. In contrast, belief-based dynamically inconsistent agents have erroneous expectations about time shocks. Correcting these beliefs will cause them to change their allocation decisions to better conform to the true state of the world.

Second, naïve present-biased agents will learn about their own present bias and update their beliefs about how they discount. ${ }^{5}$ This will increase commitment demand for time-use choices made far in advance. If agents have biased beliefs over time shocks, however, this prediction need not hold. Information on past dynamically inconsistent decisions should help optimistic agents bring their beliefs in line with the true state, but this does not necessarily lead them to demand costly commitment (Laibson, 2015).

We tested these predictions by conducting an experiment over two weeks. The first week provided a baseline measure of dynamically inconsistent behavior for each subject. On the first day of the experiment, subjects divided their required tasks between a period later that day and a period two days in the future. Subjects were able to pay a price in terms of additional tasks to commit to this morning choice. ${ }^{6}$ On the evening of day 1, subjects could revise their task allocation, conditional on the

\footnotetext{
${ }^{3}$ Again, in the quasi-hyperbolic model of Laibson (1997), naïve agents have true discounting parameters $\beta$ and $\delta$ but believe their present-bias parameter is $\hat{\beta}$ where $\beta<\hat{\beta} \leq 1$.

${ }^{4} \mathrm{~A}$ recent working paper by Browning and Tobacman (2015) makes a similar theoretical argument. Gabaix and Laibson (2017) show that a similar identification problem can occur due to imperfect (but unbiased) forecasting of the future.

${ }^{5}$ For instance, an agent might learn that she has a lower $\beta$ than previously thought.

${ }^{6}$ This in-kind price could take on both positive and negative values.
} 
morning commitment decision. Procrastination was indicated by the subject moving tasks to the later date. In addition, we gathered information on routine time use and subjects' predicted and actual bedtimes so we could compare task allocation behavior to real-world effort decisions. At the beginning of week 2, treated subjects were presented with information on their own task procrastination and on how well they were able to forecast their own bedtimes. To reduce the possibility of experimenter demand effects, this information was cast as a neutral reporting of past behavior. All subjects then engaged in the same task decisions as in week 1.

Our experimental results indicate that both beliefs and discounting are important determinants of time inconsistency. Evidence on beliefs comes from testing the effect of treatment on task allocation. The marginal effect of postponing a task in week 1 on postponement in week 2 is statistically significant and positive for control subjects, but approximately zero for treated subjects. That is, treated subjects procrastinated less in week 2 than their week 1 behavior would predict. This is consistent with beliefbased dynamic inconsistency and inconsistent with discounting-based dynamic inconsistency. Evidence on present-biased utility comes from testing the effect of treatment on commitment demand in week 2 for individuals who were procrastinators in week 1. For these individuals, treatment increased week 2 commitment demand, consistent with discounting-based dynamic inconsistency. Heterogeneity analysis using baseline measures of naïvete about time preferences and time shocks shows that these results are stronger for naifs.

Next, we employ matching to classify individuals' behavior as belief based, discounting based, or both. If a dynamically inconsistent treatment group member reduced the amount of work put off in week 2 more than her control group peer, we classify the subject's behavior as belief based. If a dynamically inconsistent treatment group member changed commitment demand more than her control group peer, we classify her behavior as discounting-based. Under this taxonomy, among subjects who changed their work allocations in week 1, 25\% of subjects exhibited discounting-based inconsistency, 39\% exhibited belief-based inconsistency, and $21 \%$ exhibited both. The remaining $15 \%$ of subjects exhibited behavior inconsistent with either model.

We then show that this dynamic inconsistency extended to consequential, realworld time use. At baseline, subjects systematically mis-predicted their own bedtimes, going to bed later than planned on average. Treated subjects reduced their forecast error in week two. Consistent with the task-based results, this reduction 
is larger for those with larger week-one forecast errors. This is evidence that the treatment affected subjects' decision problem in the time domain. To investigate this effect further, we collected a panel of time use data from subjects over the course of the experiment. Panel data on time use is rare (Frazis and Stewart, 2012), and it allows us to examine how our treatment affected behavior outside the experiment. We show that when subjects were randomly induced to spend more time on our experiment, on average they spent less time studying and working, but more time watching television.

This study provides evidence on the sources of dynamically inconsistent behavior and the real-world consequences of such behavior. We observe procrastination in a controlled setting and tie that behavior to consequential decisions like the timing and duration of sleep (Gibson and Shrader, 2019). Firms may be exploiting time inconsistency in sleep decisions and elsewhere. For instance, Netflix CEO Reed Hastings has argued that tempting services like streaming video may affect sleep decisions: "We're competing with sleep, on the margin." If individuals want to avoid such lures, the appropriate action depends on the source of their time inconsistency. The policy prescription from the time inconsistency literature has primarily been to encourage commitment by sophisticated present-biased agents. Workers are often urged to contribute to retirement plans with early withdrawal penalties or to commit to smoking cessation through a website like stickK.com. Our results suggest that this policy prescription is, at best, incomplete. If some procrastination instead stems from overestimation of future earnings or underestimation of how difficult it will be to quit smoking, then organizations and individuals seeking to correct dynamic inconsistency should provide personalized information as well. This hypothesis is consistent with the widespread sale of goods - like fitness trackers and planners - that help consumers reflect on execution of their own plans. ${ }^{7}$ Models of long-run forecasting errors due to bounded rationality (Gabaix, 2014) similarly suggest that targeted information may correct consistent planning errors.

In addition, our study makes two contributions related to the demand for costly commitment. First, our findings help explain the widely observed, low take-up of such commitment. Subjects whose dynamic inconsistency originates solely from optimism will not demand costly commitment. Schilbach (forthcoming) notes that in

\footnotetext{
${ }^{7}$ Paul Krugman has made this point when reflecting on his own fitness tracker use, writing that "what fitness devices do, at least for me, is make it harder to lie to myself."
} 
the majority of experiments subjects were either unwilling to pay for commitment or were willing to pay only very small amounts. (In a significant exception, Schilbach does find high demand for commitment in the domain of alcohol consumption.) Second, our experimental design makes a methodological contribution in its elicitation of commitment demand. Our design begins from the convex time budget techniques of Andreoni and Sprenger (2012a). ${ }^{8}$ Specifically, it uses real-effort tasks similar to those employed by Augenblick et al. (2015) and hews closely to the overall experimental design of that paper to clarify the importance of belief-based dynamic inconsistency. In contrast to Augenblick et al. (2015), our commitment price is denominated in tasks rather than money. ${ }^{9}$ By keeping all choices in the task domain, we reduce the tendency of commitment demand to spike sharply at a zero price. We find that $20 \%$ of subjects were willing to commit to their time use choices at positive task-denominated prices.

Finally, our results contribute to a growing body of research demonstrating the importance of a decision maker's beliefs in how they make choices involving time. DellaVigna and Malmendier (2006) and Acland and Levy (2015) both study gym membership and attendance, showing that consumers systematically overestimate how often they will go to the gym in the future even when this choice entails monetary costs. Börsch-Supan et al. (2018) demonstrate that a much larger portion of regret about not having saved more earlier in life is explained by positive and negative financial shocks than present bias. Consistent with the common lack of commitment demand in experimental subjects, Augenblick and Rabin (forthcoming) find that individuals' predictions about the choices they will make in the future suggest that they don't understand their own present bias. Furthermore, subjects who make choices for the future immediately after completing tasks volunteer for less work in the future than those asked just before completing tasks. While the authors interpret this as evidence of projection bias, it is also consistent with decision makers who are optimistic about their desire to complete future tasks, but who update after getting information.

The paper proceeds as follows. Section 2 presents the models of time inconsistency

\footnotetext{
${ }^{8}$ The approach here differs from previous convex time budget experiments in that it does not vary the rate at which subjects trade off between present and future consumption. This simplifies the experiment and its instructions but does so at the cost of not being able to estimate discounting parameters. For an overview of designs used to estimate time preferences, see Frederick et al. (2002).

${ }^{9}$ To the best of our knowledge Toussaert (2018) is the only other experiment that elicits commitment demand with prices denominated in tasks.
} 
due to discounting parameters versus optimism and lays out predictions. Section 3 gives the experimental design. Section 4 describes the data. Section 5 presents results. Section 6 concludes.

\section{Theory and Hypotheses}

A decision maker is given tasks and is deciding what time to go to bed. ${ }^{10}$ For every waking hour past 9 p.m. she suffers increasing, convex, twice differentiable costs. Additionally, at 9 p.m. a time shock is realized (imagine that this is a problem set to finish, a call from a family member, or an appealing TV show).

We give the decision maker $w$ tasks, which she is allowed to split between two days as $w_{1}$ and $w_{2}$. On night $t$, the decision maker faces a time value shock, denoted $\theta_{t}$, which is always weakly positive. $\theta_{t}$ has a distribution $F\left(\theta_{t} ; \alpha_{t}\right)$, where $\alpha_{t}$ is an index on the distribution such that if $\alpha>\alpha^{\prime}$, then $F\left(\theta_{t} ; \alpha\right)$ first order stochastically dominates $F\left(\theta_{t} ; \alpha^{\prime}\right)$. These shocks are independently distributed. The decision maker discounts at rate $\delta$ and may be present biased with $\beta \leq 1$. When deciding how to split up these tasks earlier in the day, she solves

$$
\min _{w_{1}} \beta \mathbb{E}^{\alpha}\left[c\left(w_{1}+\theta_{1}\right)+\delta c\left(w-w_{1}+\theta_{2}\right)\right]
$$

When given the same decision after the time shock is observed and immediately before the work has to be done, the decision maker instead chooses a workload to solve

$$
\min _{w_{1}} c\left(w_{1}+\theta_{1}\right)+\beta \delta \mathbb{E}^{\alpha}\left[c\left(w-w_{1}+\theta_{2}\right)\right] .
$$

Previous research has demonstrated that individuals tend to make choices that appear present biased: on average, they allocate more work to the earlier date when the decision is made for the future compared to when it is made in the present. A popular way to model present bias is through the use of $\beta-\delta$ preferences, in which $\delta$ captures the standard "exponential" part of discounting, while $\beta$ is the "present

\footnotetext{
${ }^{10} \mathrm{We}$ focus on the bedtime decision for a number of reasons. First, in the empirical application, we want to examine consequential, real-world effort decisions in addition to behavior on laboratory tasks. Almost all individuals sleep every day but do not necessarily engage in other effort decisions on a daily basis. Second, the bedtime decision occurs at the end of the day, which means that all realized time shocks during the day impinge on the bedtime decision.
} 
bias" parameter, which places a lower weight on all future sources of utility (Laibson, 1997).

The $\beta-\delta$ model is used in part because it generates the dynamic inconsistency that is often seen in choice data. The inconsistency arises from the difference in how the decision maker trades off utility coming from dates 1 and 2 when the decision is made at or before date 1 . In the former case, the rate of discount between the two periods is $\beta \delta$, while in the latter it is $\delta$.

While choice revisions can arise from present bias, they can also arise from biased beliefs. For instance, a decision maker might be solving problem 1 under the belief that the distribution she's facing at date 1 is $F\left(\theta ; \alpha^{\prime}\right)$ while the true distribution she faces is $F(\theta ; \alpha)$ for $\alpha>\alpha^{\prime}$. In this case, the shocks she faces at date 1 will tend to be surprisingly high, and she will want to complete fewer tasks today.

We do not model the source of incorrect beliefs, instead taking them as given and studying their implications. However, a number of existing models could lead to these optimistic beliefs. Kahneman and Tversky (1982) coined the term "planning fallacy," and provided an intuitive model in which decision makers neglect distributional information, leading to optimistic beliefs about outcomes like task duration or earnings. Beliefs and updating rules have also been modeled as a choice variable from the point of view of the decision maker (Bénabou and Tirole, 2002, Brunnermeier and Parker, 2005, Brunnermeier et al., 2016). Agents in these models trade off between the distortions caused by incorrect beliefs and their benefits, such as improved self-esteem or higher motivation. In concordance with these theoretical results, there is evidence that subjects don't update their beliefs according to Bayes' rule (Falk et al., 2006, Eil and Rao, 2011). Although these different models are important for the welfare implications of an intervention to reduce bias in beliefs, they are not important for the purposes of this study - to assess the roles of beliefs and discounting in dynamically inconsistent behavior.

There is a great deal of evidence suggesting that decision makers exhibit optimistic beliefs about the future. Roy et al. (2005) survey the literature on the planning fallacy, in which individuals underestimate the length of time it will take to complete tasks. This optimism is found in situations as diverse as predicting the amount of time it takes to fill out tax forms and predicting the amount of time one will have to wait in line for gas. Similarly, people have a tendency to think they are more likely than their peers to experience positive events and less likely to experience negative events 
(Taylor and Brown, 1988). One form of optimism which has broad economic effects is overconfidence. Research has shown that individuals are systematically overconfident with the vast majority thinking they are smarter (Larwood and Whittaker, 1977) or better drivers (Svenson, 1981) than their average peer. This overconfidence continues to be experimentally observable even when it is costly to the decision makers (Camerer and Lovallo, 1999, Niederle and Vesterlund, 2007). It also manifests in decisions outside of the lab, such as changing patterns in corporate investment and mergers (Malmendier and Tate, 2005, 2008) and job search behavior (Mueller et al., 2018). These sorts of excess optimism and overconfidence might lead decision makers to start a task later than they expected or fail to save sufficiently in a way that makes them appear present biased.

Both belief-based and discounting-based dynamic inconsistency are consistent with behavior that looks like procrastination: planning to do work, and then putting it off to a later date when given the chance. Our experimental data allow us to test whether this behavior appears on average in the population, giving us our first hypothesis.

Hypothesis 1 For both models, individuals will allocate more work to the earlier time period when making decisions for the future than when making decisions for the present.

In models where decision makers are aware of their present bias, they have an incentive to seek out commitment. While previous work has found evidence of present bias, evidence for commitment demand has been more elusive. One explanation is that individuals are unaware of their present bias, or are "naïve" in the sense that they believe that their $\beta$ parameter is closer to 1 than it actually is. This implies that individuals will systematically mis-predict their future actions. For instance, if the costs of staying up too late are felt in the future, then a decision maker will stay up later than she previously planned.

Not surprisingly, having biased beliefs about the shocks she will face in the future will also lead a decision maker to mis-predict her future actions. If beliefs are "optimistic" in the same way that would cause decision makers to postpone work, then a decision maker will also predict that she will go to sleep earlier than she actually does. Thus both of the models discussed here make the same prediction when it comes to decisions for the future.

Hypothesis 2 For both models, when making predictions for the future, individ- 
uals will expect to go to sleep earlier than they actually end up going to sleep.

Models of biased beliefs and present bias generate the same predictions for the cases discussed thus far, and in general are consistent with existing empirical results in the dynamic inconsistency literature. Because both models rely on beliefs (either over $\alpha$ or $\beta$ ) being incorrect to generate patterns seen in the data, one way to differentiate between the two models is to observe the effects of information provision on subsequent choice. Suppose the decision maker is given the information that when making past choices, the amount of work she agreed to earlier in the day was higher than the amount of work she chose at 9 p.m. This could cause the decision maker to update to a higher belief about $\alpha$, a lower belief about $\beta$, or both. The predicted responses to these two types of updating differ for work allocations and commitment.

In the naïve $\beta$ - $\delta$ model, the decision maker has incorrect beliefs about the present bias parameter that will govern her decisions in the future. In prior work, researchers have typically interpreted a lack of commitment demand by individuals as evidence that $\hat{\beta}$, the individual's belief about her own present bias, is closer to one than to $\beta$, the "true" present bias. A decision maker's belief about her own $\beta$ affects what she believes she will choose in the future. Because the decision maker cares about what her future self is choosing, a change in these beliefs might lead to changes in her willingness to commit or changes in her actions in the present, to compensate for decisions that will be made in the future (O'Donoghue and Rabin, 1999).

When applied to the decision problem described above, this $\hat{\beta}$ only affects the decision maker's willingness to commit - not the allocative choices that she makes when either committed or uncommitted. Only a single decision is ever implemented, so beliefs about what will be done in the future won't affect those decisions. Essentially, while $\beta$ does affect the solution to the problem in Equation (2), beliefs about $\beta$ do not.

Hypothesis DB1 Information provision will have no effect on work allocations for discounting-based dynamically inconsistent agents.

While changing beliefs about one's present bias will not affect work allocations, changing beliefs about the distribution of the state variable will. In particular, we expect individuals who reallocated work into the future to update towards a distribution with a higher $\alpha_{1}$ : shocks were worse on the first night than they thought. On the other hand, if on the first night they reallocated work into the present, we might expect them to believe in a lower $\alpha_{1}$ (a more favorable distribution). Thus we have 
the prediction that when given information, a decision maker whose beliefs are biased will display more consistency between her present and future choices.

Hypothesis BB1 Information provision will decrease the difference between future and present allocations for belief-based dynamically inconsistent agents.

These two models also have implications for how commitment demand changes after receiving information. Suppose this decision maker is choosing between the payoffs from equations (2) and (1). Whether commitment or flexibility is preferred depends on $w$ in equation 1 . We are interested in the value that makes the decision maker indifferent between commitment and flexibility. To that end, we examine the comparative statics with respect to $\hat{\beta}$ and $\alpha_{1}$. With the uncommitted and committed choices denoted by $w^{N C}\left(\theta_{1}, \beta\right)$ and $w^{C}\left(\alpha_{1}, \beta\right)$, the indifference point $x\left(\alpha_{1}, \hat{\beta}\right)$ is implicitly defined by

$$
\begin{aligned}
& \mathbb{E}\left[c\left(w_{1}^{N C}\left(\theta_{1}, \hat{\beta}\right)+\theta_{1}\right)+\delta c\left(w-w_{1}^{N C}\left(\theta_{1}, \hat{\beta}\right)+\theta_{2}\right)\right] \\
& \quad=\mathbb{E}\left[c\left(w_{1}^{C}\left(\alpha_{1}, x\left(\alpha_{1}, \hat{\beta}\right)\right)+\theta_{1}\right)+\delta c\left(x\left(\alpha_{1}, \hat{\beta}\right)-w_{1}^{C}\left(\alpha_{1}, x\left(\alpha_{1}, \hat{\beta}\right)\right)+\theta_{2}\right)\right]
\end{aligned}
$$

Notice that when imagining what allocation will be chosen in the future while facing problem (2), a naïve $\beta-\delta$ discounter believes that the first order conditions which will be satisfied are

$$
c^{\prime}\left(w_{1}^{N C}\left(\theta_{1}, a_{1}, \hat{\beta}\right)+\theta_{1}\right)=\hat{\beta} \delta \mathbb{E}\left[c^{\prime}\left(w-w_{1}^{N C}\left(\theta_{1}, \hat{\beta}\right)+\theta_{2}\right) \mid \theta_{1}\right]
$$

Furthermore, it is clear that $\frac{d w_{1}^{N C}\left(\theta_{1}, \hat{\beta}\right)}{d \hat{\beta}}>0$. Taking a total derivative of the equality above and plugging in the first order conditions for $w_{1}^{C}$, we get

$$
\begin{array}{r}
\mathbb{E}\left[\left[c^{\prime}\left(w_{1}^{N C}\left(\theta_{1}, \hat{\beta}\right)+\theta_{1}\right)-\delta c^{\prime}\left(w-w_{1}^{N C}\left(\theta_{1}, \hat{\beta}\right)+\theta_{2}\right)\right] \frac{\partial w_{1}^{N C}}{\partial \hat{\beta}}\right] \\
=\mathbb{E}\left[\delta c^{\prime}\left(x\left(a_{1}, \hat{\beta}\right)-w_{1}^{C}\left(\alpha_{1}, x\left(\alpha_{1}, \hat{\beta}\right)\right)+\theta_{2}\right) \frac{\partial x}{\partial \hat{\beta}}\right]
\end{array}
$$

The first order conditions given in equation (3) imply that for $\hat{\beta}<1$ the left hand side will always be negative. Then $\frac{\partial x}{\partial \hat{\beta}}$ must be negative, implying that as $\hat{\beta}$ increases (i.e. decision makers believe that they are more time consistent) the amount of work they must be given to get them to commit goes down - it is harder to get them to 
commit. This gives us a prediction for how information provision should affect a naïve present biased individual's demand for commitment.

Hypothesis DB2 Discounting-based dynamically inconsistent individuals who reallocated work from the present to the future will increase commitment demand when provided with information.

The effect of information provision on the commitment demand of an individual with biased beliefs is more ambiguous; in general a clear prediction cannot be made without stronger assumptions either on the structure of decision makers' cost functions, or the distribution of shocks that they face. Even a first order stochastic dominant shift in the distribution can push demand in either direction.

\section{Experimental Design}

We implemented a longitudinal experiment to test these hypotheses. Undergraduate subjects were recruited through an online system to four different sessions throughout the semester and participated in the experiment for two weeks. To complete the study, subjects were required to complete eight surveys on the mornings of Monday through Thursday of each week and four sets of tasks in the evenings of Monday and Wednesday of each week. All surveys and tasks were distributed through Qualtrics.

To begin, subjects completed an introductory session in a lab. Subjects were first read an overview of the timeline and requirements of the study. They then logged on to the computer to complete a survey that included basic demographic information as well as a measure of present bias. The survey then presented five sample tasks for subjects to complete, and explained how the allocation and commitment decisions would be made. Finally, subjects were required to complete a comprehension quiz before advancing.

After the introductory session, all surveys and tasks were completed outside of the lab on subjects' own devices. ${ }^{11}$ Subjects were required to complete surveys and tasks at particular times. A link to each survey was sent out at 6 a.m. and subjects were instructed to complete the survey before noon that day. At noon, subjects who had not completed the task were sent a reminder and had two hours to complete the survey. If they did not complete the survey by 2 p.m., they were dropped from the

\footnotetext{
${ }^{11}$ While it was possible to complete the surveys on a smartphone, the task interface was easier to use on a computer.
} 
study. A link to the tasks was sent out at 9 p.m. and tasks had to be completed before 4 a.m. the next morning.

\subsection{Tasks}

Figure 1: The first four sliders of a task

Task 1

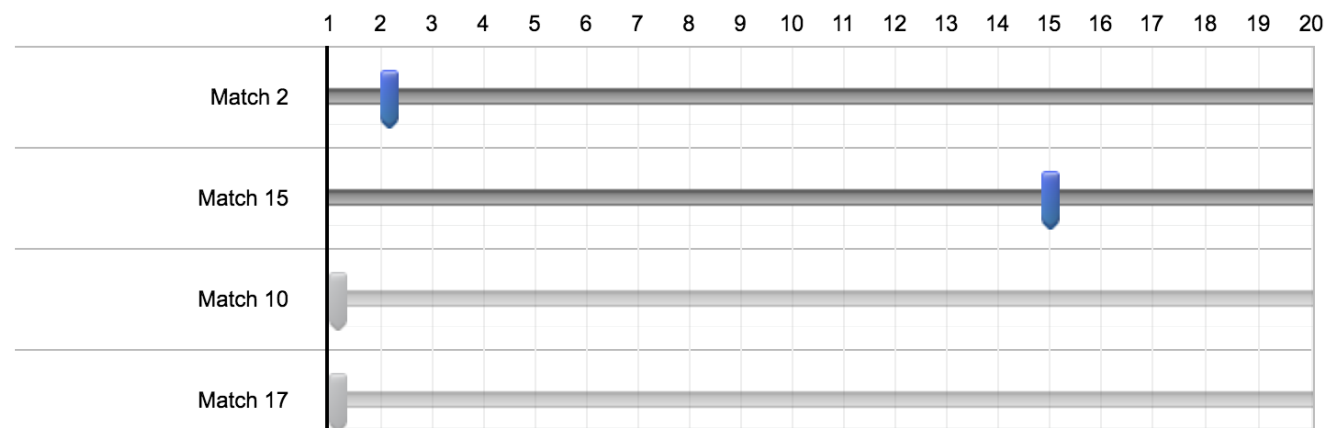

Notes: The figure shows the beginning of a task, showing the first four required sliders. Two of the sliders have been aligned and two remain to be aligned.

The tasks that subjects were required to complete consisted of moving sliders to match particular, predetermined levels. Slider tasks have proven useful in experimental settings as tasks that require real effort and focus from subjects (Gill and Prowse, 2012). In other experimental work, subjects have been required to set each slider to its midpoint, with the sliders offset to make the task more difficult. The software we employed did not allow sliders to be offset, so the required level of each slider was varied to increase difficulty. The order of the sliders was randomized for the same reason.

A single task consisted of moving nineteen sliders. ${ }^{12}$ Each page included no more than 10 tasks, and subjects were unable to proceed to the next page if the current page was incomplete or if there were any errors. If subjects tried to proceed in these cases, they were informed that the task had a problem, but were not told which slider was incorrect. Figure 1 presents the first four sliders of an example task. The tasks

\footnotetext{
${ }^{12}$ Each slider was initialized at the number one, but had to be clicked before it became active. To avoid subjects becoming confused at their tasks not being accepted due to an inactive slider, the number one was omitted from the potential target levels.
} 
were designed so that each would take about one minute to complete. The median time spent per task by actual subjects was 1 minute and 20 seconds.

\subsection{Allocation Decisions and Commitment}

Subjects made two allocation decisions each week. Each allocation decision consisted of how to divide 10 tasks between Monday and Wednesday evenings. The first allocation was made when completing a survey on Monday morning, imposing at least a seven hour delay between when the allocative decision was made and when the tasks were actually carried out. The second allocation was made immediately before completing the tasks on Monday evening.

In addition to allocating tasks across evenings, subjects were also offered the chance to "commit," increasing the probability that the morning allocation would be the one implemented. If the subjects did not commit they had a one-in-five chance of the morning allocation being implemented. If the subjects did commit this probability rose to four out of five. The commitment was probabilistic rather than deterministic to preserve the incentive compatibility of the evening choices.

To elicit subjects' demand for commitment, they were given the choice of whether or not to commit at a variety of prices, both positive and negative. Due to previous work, including Augenblick et al. (2015), suggesting that many subjects' moneydenominated willingness to pay for commitment is near 0 , the prices were denominated in terms of mandatory tasks that would have to be done each night in addition to the tasks that were allocated to that night. Mandatory tasks could potentially vary between 4 and 16, depending on a subject's choices and which choice was implemented. A portion of the price list subjects faced can be seen in Figure 2.

\subsection{Sleep and Time Use Measurements}

Both expected and actual bedtimes were elicited from subjects. In each morning survey, subjects were asked when they went to sleep the night before. Additionally, subjects were asked both in the morning and evening survey at what time they expected to go to sleep that night. These predictions were deliberately not incentivized for two reasons. The first was to avoid confounding: an incentivized prediction could have affected both task allocation and commitment demand. The second was to test for broad treatment effects on intertemporal optimization that were not attributable 
end of the week to sync the sleep measurements. ${ }^{14}$

\title{
3.4 Information Treatment
}

In the second week of the study, treated subjects were given information about their own past choices. The treatment, an example of which can be seen in Figure 3, consisted of three main parts. The first described the allocation choices that the individual made the week before, emphasizing whether or not any tasks were reallocated on Monday evening. The second part reported the subject's average actual and predicted bedtimes and gave the difference between them in minutes. Finally, treated subjects were asked why someone's choices and predictions might change throughout the day. Subjects were given a blank space in which they had to type something to proceed.

Figure 3: Treatment

\section{Choosing the Implemented Allocation}

\begin{abstract}
Last week, on Monday morning you said you'd do 15 tasks on Monday evening and 7 tasks on Wednesday. When you were asked in the evening, you decided to do 16 on Monday, and 6 on Wednesday. Thus, you moved 1 task from Wednesday to Monday.

Also, on average you predicted that your bedtime would be 12:30 AM, and your actual average bedtime was 1:42 AM, so you missed your predicted bedtime by about 72 minutes.
\end{abstract}

Why might someone's choices and predictions change throughout the day?

There may be unforeseen things that pop up throughout the day that keep them busier than they thought or they miscalculate how long something will take

Notes: An example of an actual message that one of the treated subjects received at the beginning of week 2 of the experiment. The information was provided to subjects just before they made commitment and allocation decisions. The text given in the box is an example of a response that a subject gave to the open-ended question about why someone's choices and predictions might change. The box was empty when subjects were presented with the message.

The treatment information was intentionally neutral to avoid experimenter demand effects. In particular, we did not use judgmental language when describing the change in task allocation. We provided subjects with information that they could

\footnotetext{
${ }^{14}$ As described below, some subjects were treated with information about their allocation and bedtime choices. To obtain bedtime information, Fitbits had to be returned to the experimenter and synced. Due to the time required to sync and recharge each Fitbit, it was infeasible to then immediately return them to the subjects. This is why subjects were not given Fitbits for the second week.
} 
have recorded for themselves had they chosen to do so. Finally, we did not mention commitment in the treatment.

This information was given to treated subjects (and only treated subjects) on Monday morning of the second week. They were shown the information after they reported their bedtime for the previous night and made a prediction for Monday night but before they made the commitment and allocation decisions.

\subsection{Payments}

Subjects received $\$ 40$ total for completing the full study. An initial payment of $\$ 10$ was made to all subjects on Thursday or Friday of the first week when they returned the Fitbit to the economics department. The second payment of $\$ 30$ was made to the subjects on Thursday or Friday of the second week, conditional on all portions of the experiment being completed on time.

\section{Data}

A total of 274 undergraduate subjects were recruited through an online system and completed the introductory session. 26 of these subjects did not complete some surveys and left the experiment only having received the initial payment of $\$ 10$. The vast majority of those who dropped out of the experiment did so in the first week of their participation. Another 39 subjects missed the completion deadlines for at least one survey, though they eventually did answer all surveys. These subjects are excluded from the primary sample, leaving a final baseline sample of 209 subjects.

Table 1 tests baseline covariate balance and the simplest hypotheses generated by our theory. We find a small imbalance in week one commitment demand, which is statistically significant at the ten percent level, and therefore control for it in estimating treatment effects. There is also imbalance in the fraction of female subjects, statistically significant at the five percent level, and again we control for this.

Figure 4 shows a histogram of subjects' commitment demand in the first week. ${ }^{15}$ As noted in Section 3, subjects were able to choose between: (a) doing 10 tasks and having a low chance of being committed or (b) doing a different number of tasks and having a high chance of being committed. A commitment demand of one indicates that the subject was willing to do one extra task to be committed, but was unwilling

\footnotetext{
${ }^{15}$ The commitment demand in week 2 is shown in Figure 8.
} 
Table 1: Treatment-control balance

\begin{tabular}{lccc}
\hline & Control & Treatment & \\
& Mean/(SD) & Mean/(SD) & Diff./(SE) \\
\hline Commitment demand week 1 & -0.92 & -0.13 & $-0.79^{*}$ \\
Work put off week 1 & $(3.04)$ & $(3.27)$ & $(0.44)$ \\
& 0.030 & 0.0092 & 0.021 \\
Bedtime difference from plan (minutes) & $(2.84)$ & $(1.87)$ & $(0.33)$ \\
& 36.1 & 39.8 & -3.68 \\
GPA & $(68.7)$ & $(53.9)$ & $(8.50)$ \\
& 3.22 & 3.31 & -0.085 \\
Female (indicator) & $(0.49)$ & $(0.47)$ & $(0.066)$ \\
& 0.54 & 0.70 & $-0.16^{* *}$ \\
Study wave & $(0.50)$ & $(0.46)$ & $(0.067)$ \\
& 2.47 & 2.56 & -0.090 \\
& $(1.13)$ & $(1.09)$ & $(0.15)$ \\
\hline Observations & 100 & 109 & \\
\hline
\end{tabular}

Notes: The significance of the differences is assessed using a $t$-test. Significance indicated by: *** $\mathrm{p}<0.01,{ }^{* *} \mathrm{p}<0.05,{ }^{*} \mathrm{p}<0.1$.

to do two. Since this elicitation method is necessarily bounded, having a commitment demand of six indicates that a subject is willing to do at least six extra tasks to be committed, while a commitment demand of negative seven indicates that the subject is unwilling to commit even if it lowers the number of tasks she must do by six.

Denominating the commitment price in tasks generated a larger spread in commitment demand than has been seen in similar experiments. Over $28 \%$ of subjects were willing to do at least one extra task in order to be committed in the first week, while over $22 \%$ were willing to do one extra task to be flexible. Of the remaining subjects whose value of commitment was near zero, just over half chose to commit at a price of zero. To facilitate comparison with previous work, we estimate equivalent cash prices as follows. The travel cost literature has estimated that people value time at roughly 72 (Lam and Small, 2001) to 93 percent (Small et al., 2005) of the wage rate. The median wage among subjects was $\$ 12$, so the implied range of values was $\$ 10$ to $\$ 13$. As median task completion time was 1 minute 20 seconds, the cash value of one task was approximately 22 to 29 cents. In contrast, Augenblick et al. (2015) find only $9 \%$ of subjects were willing to pay $\$ 0.25$ to be committed, and $10 \%$ of subjects were willing to pay $\$ 0.25$ for flexibility. 
Figure 4: Commitment demand in week 1

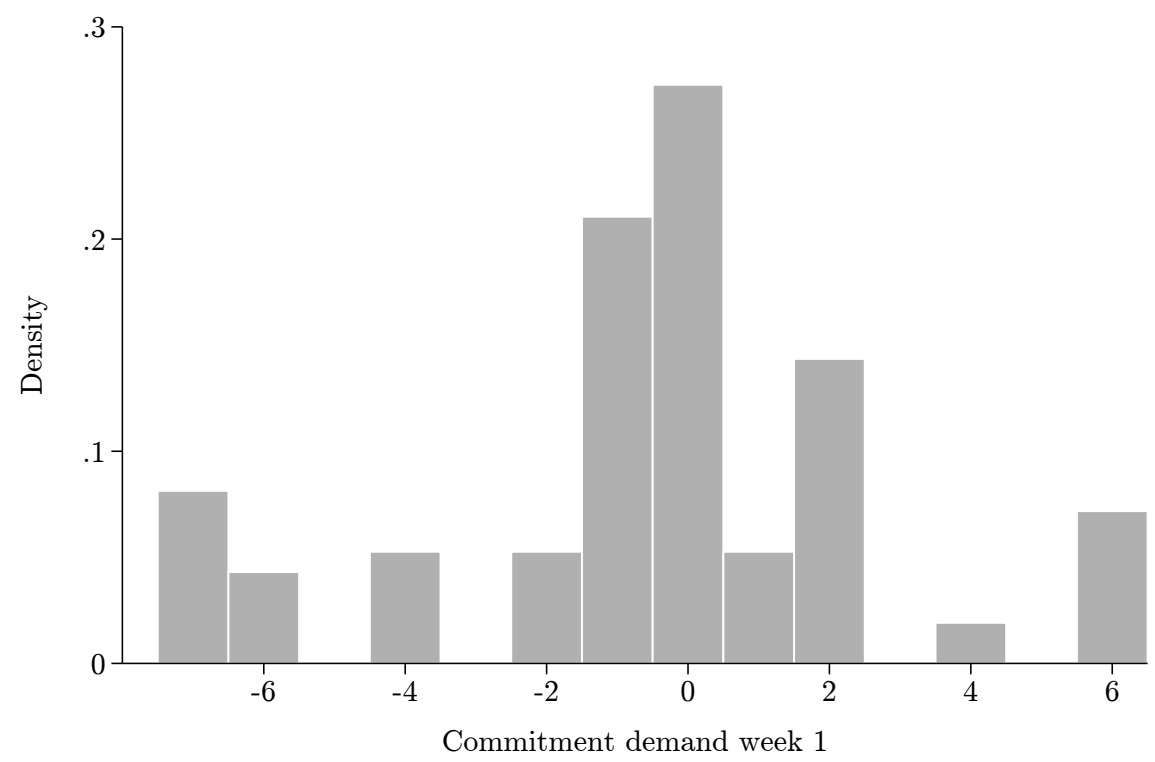

Notes: The figure shows the distribution of commitment demand for subjects in week 1 , before treatment. The $x$-axis shows the price paid for commitment in terms of extra tasks.

Table 2 summarizes attrition in the experiment. Column 1 presents means for the 64 subjects $(23 \%)$ who did not complete the experiment and Column 2 presents means for those who did, pooling treatment and control. There are no statistically significant differences across the two groups. Appendix Table 8 reports results from a regression of a study completion dummy on observable characteristics from our baseline survey. Point estimates are uniformly small, and none are statistically significant.

\section{Results}

\subsection{Tests of Hypotheses}

In this section we test the five hypotheses from the theory presented in Section 2. The first two hypotheses are about procrastination and missed time use plans. Hypothesis 1 predicts that on average, agents will postpone work in the evening, relative to their planned morning allocation. Consistent with this hypothesis, we do see a positive average value of "Work put off week 1" in Table 1, though this value is not statistically significant. Putting off work was potentially costly for subjects. If they had put off 
Table 2: Observables by attrition status

\begin{tabular}{lccc}
\hline & $\begin{array}{c}\text { Did not finish } \\
\text { Mean/(SD) }\end{array}$ & $\begin{array}{c}\text { Finished study } \\
\text { Mean/(SD) }\end{array}$ & Diff./(SE) \\
\hline Treat & 0.44 & 0.52 & -0.084 \\
& $(0.50)$ & $(0.50)$ & $(0.072)$ \\
Age & 20.2 & 20.5 & -0.23 \\
& $(1.55)$ & $(1.83)$ & $(0.25)$ \\
GPA & 3.19 & 3.27 & -0.074 \\
& $(0.49)$ & $(0.48)$ & $(0.069)$ \\
Female (indicator) & 0.56 & 0.62 & -0.060 \\
& $(0.50)$ & $(0.49)$ & $(0.070)$ \\
Study wave & 2.38 & 2.52 & -0.14 \\
& $(1.15)$ & $(1.11)$ & $(0.16)$ \\
\hline Observations & 64 & 209 & \\
\hline
\end{tabular}

Notes: The significance of the differences is assessed using a $t$-test. Significance indicated by: ${ }^{* * *} \mathrm{p}<0.01,{ }^{* *} \mathrm{p}<0.05,{ }^{*} \mathrm{p}<0.1$.

work and had then been unable to complete the tasks, they would have been dropped from the experiment and would have been ineligible for full compensation.

Hypothesis 2 predicts that agents will miss their planned bedtimes. Under the assumption that the bedtime plans that subjects reported to us were their expectations in the technical sense, we can compare the distributions of planned and actual bedtimes. The average values for "Bedtime difference from plan" in Table 1 indicate that agents miss their planned bedtimes by 36 to 40 minutes. This difference is significantly different from zero (the standard error is 4.24). Subjects were not incentivized to meet their bedtime plans, reducing the potential that subjects changed their bedtime behavior to match their predicted bedtime more closely. Anchoring effects from asking for bedtime predictions, however, could still cause subjects to reduce their prediction error (Tversky and Kahneman, 1992). Together, these results show that agents exhibit dynamic inconsistency in both task allocation and time allocation.

Next, we examine Hypothesis DB1 and Hypothesis BB1 by estimating variants of the following equation.

Postponed $_{i 2}=\gamma_{0}+\gamma_{1}$ Treat $_{i 2}+\gamma_{2}$ Postponed $_{i 1}+\gamma_{3} \operatorname{Treat}_{i 2}$ Postponed $_{i 1}+\mathbf{x}_{i}^{\prime} \xi_{1}+\varepsilon_{1, i 2}$ 
where Postponed Pit $_{\text {is }}$ the number of tasks put off by subject $i$ in week 1 or 2 , Treat $t_{i 2}$ is an indicator for being in the treatment group in week $2, x_{i}$ is a vector of control variables, and $\varepsilon_{1, i 2}$ is the stochastic error term associated with this regression. The control variables vary by specification. First, we report results with indicators for study wave (randomization into treatment was conditional on wave). Second, we add gender, age, and age squared. Finally, we add controls for past grade point average (GPA), self-reported busyness during week 1, and employment.

Table 3: Effect of treatment on work postponed

\begin{tabular}{lccc}
\hline & $\begin{array}{c}(1) \\
\text { Work put off } \\
\text { week 2 }\end{array}$ & $\begin{array}{c}(2) \\
\text { Work put off } \\
\text { week 2 }\end{array}$ & $\begin{array}{c}(3) \\
\text { Work put off } \\
\text { week 2 }\end{array}$ \\
\hline Treat & 0.31 & 0.37 & 0.29 \\
Work put off week 1 & $(0.38)$ & $(0.37)$ & $(0.39)$ \\
& $0.33^{* *}$ & $0.33^{* *}$ & $0.34^{* *}$ \\
Treat $\times$ Work put off week 1 & $(0.14)$ & $(0.14)$ & $(0.14)$ \\
& $-0.41^{* *}$ & $-0.43^{* *}$ & $-0.42^{* *}$ \\
\hline Wave controls & $(0.20)$ & $(0.21)$ & $(0.21)$ \\
Demographic controls & Yes & Yes & Yes \\
Additional controls & No & Yes & Yes \\
Adj. R ${ }^{2}$ & No & No & Yes \\
Observations & 0.03 & 0.02 & 0.04 \\
\hline Notes: The & 209 & 209 & 209 \\
\hline
\end{tabular}

Notes: The table shows results from estimating equation 4. Each column shows the results of a separate regression. All regressions include study wave indicators. Demographic controls are gender, age, and age squared. Additional controls are GPA, GPA squared, selfreported busyness during week 1 , and an indicator for whether the subject was employed at the time of the study. In parentheses are heteroskedasticity-robust standard errors (White, 1980). Significance indicated by: ${ }^{* * *} \mathrm{p}<0.01,{ }^{* *} \mathrm{p}<0.05,{ }^{*} \mathrm{p}<0.1$.

Table 3 presents results based on versions of estimating equation (4). The estimates are similar across the specifications. In all cases, the estimates show that for agents that did not postpone work in week 1, treatment has a positive but imprecise effect on work postponed in week 2 . The second coefficient in each column shows that postponing work in week 1 is positively and significantly associated with postponing work in week 2. Finally, the third coefficient shows that, for subjects who postponed work in week 1 , the treatment caused a significant and substantial reduction in postponement of tasks in week 2 . 
The magnitudes of the effect of work postponed in week 1 and the interaction term are similar but the signs are opposite, so the marginal effect of postponing a task in week 1 on treated subjects is approximately zero. Subjects who are reminded of their past procrastination procrastinate less in week 2 than their week 1 behavior would otherwise predict.

This effect provides evidence against Hypothesis DB1, that information provision will have no effect on work allocation. Because a naïve $\beta-\delta$ agent's allocation depends on present bias (and not beliefs about present bias), Hypothesis DB1 implies a zero coefficient on the interaction of treatment and postponed work in week one. The agent may update her belief $\hat{\beta}$, but this affects commitment demand, not task allocation. The estimates are consistent with Hypothesis BB1 that information provision will decrease the difference between present and future allocations. This is our first empirical evidence that biased beliefs (optimism) influence time-inconsistent behaviors.

We report heterogeneity analysis for this effect in Table 11. Each morning, subjects provided self-reported measures of how busy they expected to be during the day. For individuals who turned out to be procrastinators but who reported, on the first day of the experiment, that they would be less busy than the median respondent, the treatment effect was roughly twice as strong as the average effect reported in Table 3. This result suggests that individuals who were naïve about their own time shocks were more strongly affected by the treatment, consistent with the theory.

Figure 5 represents the estimate from Table 3, Column 1 graphically. The points in the figure show conditional expectations of work postponed in week 2 for each level of work postponed in week 1 , broken down by treatment and control groups. The hollow circles show conditional averages for the control group and the lighter-colored, gray line shows a linear fit through these points. The upward slope of the fitted line matches the estimate of the coefficient on work put off in week 1 , showing that for untreated individuals, putting off work in week 1 predicts putting off work in week 2 . The black circles and flat fitted black line show the approximate zero marginal effect of past work postponed on treated individuals. The figure reinforces the conclusion that our information treatment alters the work allocation of procrastinators.

To understand whether the effects in week 2 operated by changing subjects' morning or evening task allocations, Appendix Table 9 presents estimates similar to Table 3 , but the dependent variable is the work that the subject chooses in the morning 
Figure 5: Average of work postponed week 2

conditional on treatment and work postponed week 1

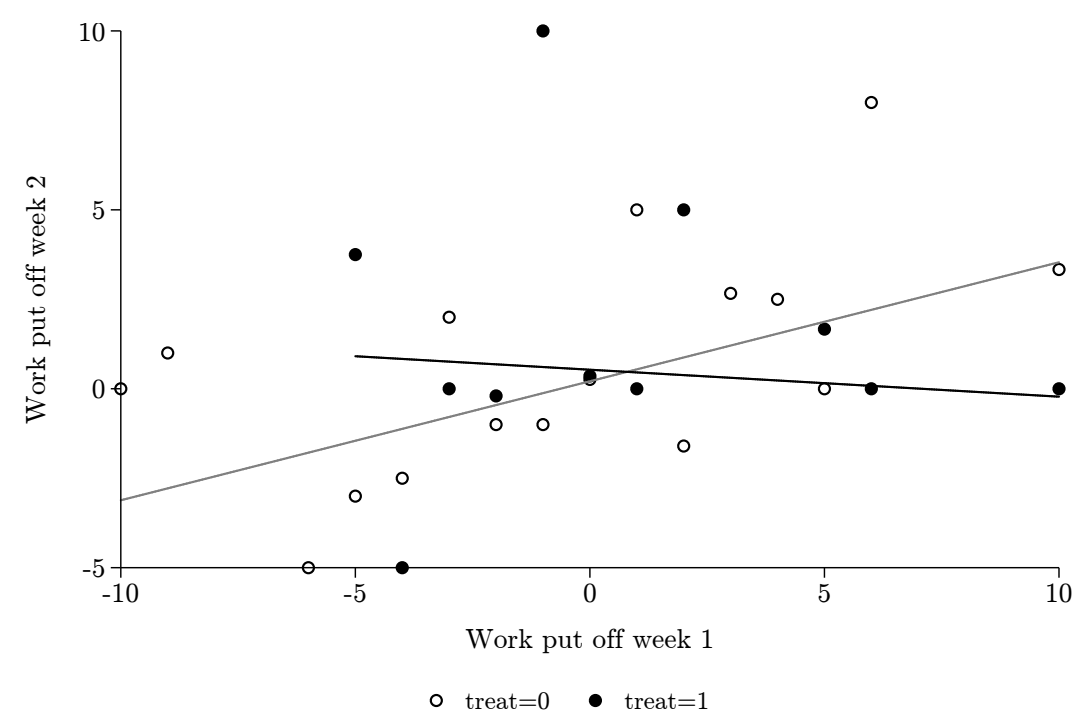

Notes: Conditional averages of raw data on work put off in week 2 at each level of work put off in week 1 , by treatment. The plot graphically reproduces the estimates similar to those in Table 3, Column 1 but without any additional covariates. The hollow circles and fitted lighter colored line show that untreated individuals are more likely to put off work in week 2 if they put off work in week 1 . The filled circles and fitted black line give the sum of the postponement and interaction estimates, showing that treated individuals are, if anything, less likely to put off work in week 2 .

(this variable comes from the morning surveys) or the tasks actually performed in the evening. Estimated effects on morning choices are broadly similar to those for tasks postponed, though less precise. Subjects who are reminded that they put off work in the prior week choose less work. This behavior is also inconsistent with Hypothesis DB1 but consistent with Hypothesis BB1.

So far, we have found evidence that subjects make dynamically inconsistent choices due to belief bias. We next test Hypothesis DB2, that treated procrastinators in week 1 will increase their commitment demand in week 2, by examining treatment effects on commitment demand. If subjects do behave consistent with DB2, that provides evidence for discounting-based dynamic inconsistency. The estimating equation models the difference in commitment demand (week two minus week one) as a function 
of treatment, interacted with measures of procrastination.

$$
\Delta \text { Commitment }_{i}=\theta_{0}+\theta_{1} \text { Treat }_{i 2}+\theta_{2} \text { Treat }_{i 2} \operatorname{Postponed}_{i 1}+\mathbf{x}_{i}^{\prime} \xi_{3}+\varepsilon_{2, i}
$$

In the equation above, $\Delta$ Commitment $_{i}$ is the change in commitment for subject $i$ between week 1 and week $2, \varepsilon_{2, i}$ is the stochastic error term for this regression, and all other variables are the same as in Equation (4). Because this is a difference specification, the level of work postponed in week 1 is subtracted out of the estimating equation.

Table 4: Effect of treatment and task procrastination on commitment demand

\begin{tabular}{lccc}
\hline & $\begin{array}{c}(1) \\
\text { Change in } \\
\text { commitment } \\
\text { demand }\end{array}$ & $\begin{array}{c}(2) \\
\text { Change in } \\
\text { commitment } \\
\text { demand }\end{array}$ & $\begin{array}{c}(3) \\
\text { Change in } \\
\text { commitment } \\
\text { demand }\end{array}$ \\
\hline Treat & -0.11 & -0.11 & -0.22 \\
Treat $\times$ Work put off week 1 & $(0.42)$ & $(0.43)$ & $(0.42)$ \\
& $0.44^{* * *}$ & $0.44^{* * *}$ & $0.45^{* * *}$ \\
\hline Wave controls & $(0.16)$ & $(0.16)$ & $(0.16)$ \\
Demographic controls & Yes & Yes & Yes \\
Additional controls & No & Yes & Yes \\
Adj. R ${ }^{2}$ & No & No & Yes \\
Observations & 0.02 & 0.01 & -0.0007 \\
\hline
\end{tabular}

Notes: The table shows results from estimating equation 5. Each column is a separate regression. Demographic controls are an indicator for gender, indicators for study wave, age, age squared, and an indicator for whether the subject was employed at the time of the study. Additional controls are GPA, GPA squared, and self-reported busyness in week 1. In parentheses are heteroskedasticity-robust standard errors (White, 1980). Significance indicated by: ${ }^{* * *} \mathrm{p}<0.01,{ }^{* *} \mathrm{p}<0.05,{ }^{*} \mathrm{p}<0.1$.

The corresponding estimates appear in Table 4. Consistent with theory, the first row shows that the effect of treatment on subjects who postpone zero tasks in week 1 is small. The second coefficient shows the interaction of treatment with tasks postponed in week one. The estimated coefficient on the interaction term is positive and statistically significant at the one percent level. This is consistent with Hypothesis DB2. Our model predicts that when a present-biased individual receives information, she will update her belief over her present bias and increase her commitment demand 
in response. The addition of demographic and busyness controls does not change the estimated coefficient.

Heterogeneity analysis, reported in Table 11, again points to these results being stronger for naifs. We interact treatment and week 1 procrastination with an indicator variable equal to 1 if, at baseline, the subject responded "yes" to a question asking whether they tend to procrastinate. The effect of treatment is much stronger for individuals who stated that they were not procrastinators but who did end up procrastinating on our experimental tasks.

Figure 6 again presents the conditional expectation version of the estimates in Table 4, Column 1. The hollow circles show the average change in commitment demand for each level of work postponed in week 1 for untreated individuals. The fitted line (light gray) shows that untreated individuals do not substantially change their commitment demand regardless of the level of work put off. The solid, black circles show the same conditional averages for treated subjects. Treated subjects substantially increase their commitment demand if they put off more work in week 1.

The results presented above refute the hypothesis that discounting alone drives dynamic inconsistency. Both beliefs and discounting are important for explaining agent behavior in this setting. Using commitment demand and task allocation behavior, we can classify individual subjects as being either time consistent, discounting-based time inconsistent, belief-based time inconsistent, or both discounting- and belief-based time inconsistent. The procedure works as follows. First, we match each treatment group subject to a single, nearest neighbor control group subject using propensity score. We use week 1 commitment demand and work put off as well as the baseline control variables for GPA, gender, age, and experiment wave to perform the matching.

Next, we estimate individual-level versions of the regressions above. ${ }^{16}$ If a time inconsistent treatment group member changed her commitment demand more than her control group peer, we classify the subject's behavior as discounting-based. If a time inconsistent treatment group member reduced the amount of work she put off in week 2 more than her control group peer, then we classify the subject's behavior as belief-based.

Using this classification, we find that conditional on changing their work allocation in week $1,85 \%$ of subjects exhibited behavior consistent with one of these two models.

\footnotetext{
${ }^{16}$ In addition to the individual-level regressions, we also estimate a finite mixture model with four latent classes. These results are reported in Table 13 of Appendix A.
} 
Figure 6: Average of change in commitment demand conditional on treatment and work postponed week 1

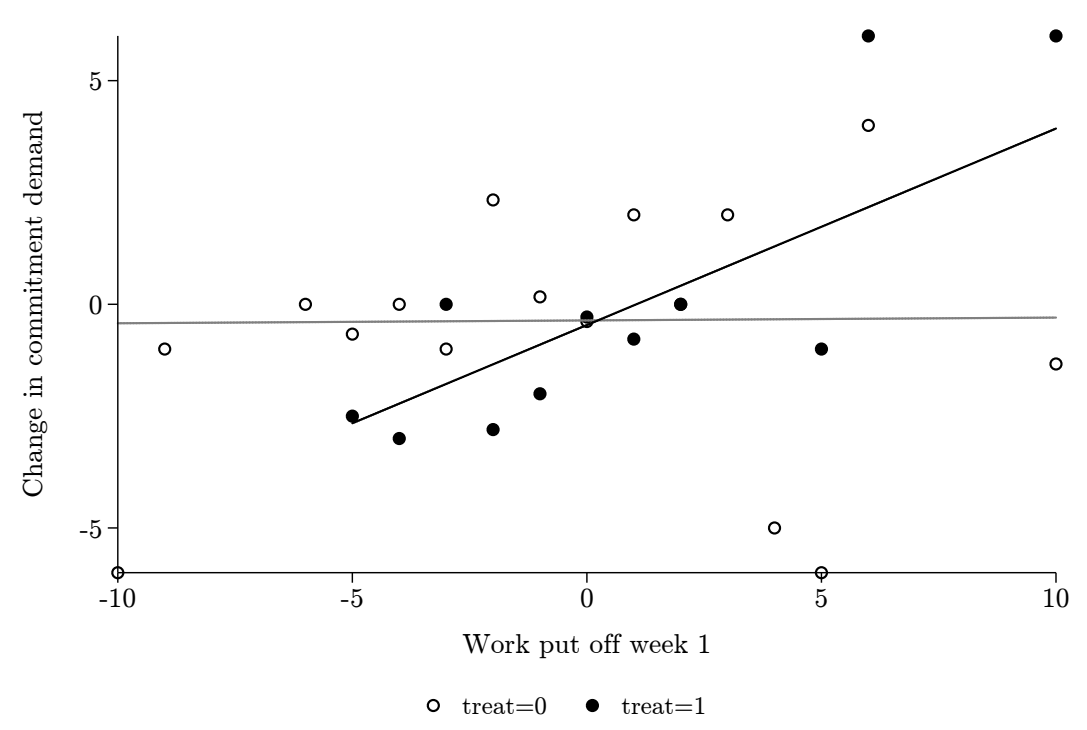

Notes: The figure shows conditional expectations of the change in commitment demand at each level of work put off in week 1 , by treatment group. The plot graphically reproduces the estimates from Table 4, Column 1. The hollow circles and fitted, lighter colored line show that untreated individuals do not change their commitment demand in week 2, on average. The filled circles and fitted black line show that treated individuals substantially increase their commitment demand if they put off more work in week 1 .

$25 \%$ of the subjects behaved in a manner consistent with discounting-based dynamic inconsistency. $39 \%$ of subjects behaved in a manner consistent with belief-based dynamic inconsistency, and $21 \%$ of subjects exhibited behavior consistent with both explanations.

\subsection{Robustness Checks}

The initial robustness checks for the headline results are presented in Tables 3 and 4. As noted in the data discussion, we do have treatment imbalance on one potentially important demographic characteristic - gender. The results in Tables 3 and 4, however, show that this imbalance did not have a substantial effect on the estimates.

Appendix Section B reports the main results, excluding subjects who switched multiple times when choosing from the commitment price list. If at any point the 
subject violates the law of demand, we classify the subject as a multiple switcher. In the results reported in the body of the paper, we include all subjects. Appendix Section B shows that whether or not these subjects are excluded, the results remain substantively unchanged.

Finally, we empirically assess experimenter demand effects by leveraging the two pieces of information given to treatment group members. Recall that treatment subjects were told about any changes in their task allocation and about deviations from their bedtime plan. Assuming that experimenter demand effects would be stronger if both of these pieces of information were consistent - for instance, if the treatment message indicated that the subject both put off tasks and delayed bedtime - and of larger magnitude, then we can asses experimenter demand by interacting bedtime prediction error with the other variables in Equations (4) and (5). We report these interaction models in Table 10. In neither case does the interaction between the bedtime error message and work put off in week 1 substantially change the conclusions from the baseline analysis. We take this as evidence against strong experimenter demand effects.

\subsection{Effect of Treatment on Time Use}

To this point we have focused on testing theoretical predictions about task choices and commitment. Our experimental design also allows us to evaluate treatment effects in another domain - real-world time use decisions and predictions. As previously described in Section 3.4, treated subjects were given information about their own time use decisions at the beginning of week 2 of the experiment.

First, we provide more detail on bedtime forecast error. In Section 5.1, we showed that, on average, subjects predicted that they would go to bed earlier than they actually did, assuming that subjects were reporting expectations of their own bedtimes to us. Figure 7 compares planned bedtimes (horizontal axis) to self-reported actual bedtimes (vertical axis) for the first night of the study. ${ }^{17}$ The majority of subjects miss their planned bedtime and appear as points above the 45-degree line, corroborating the earlier finding that subjects are generally optimistic about their bedtime plans. A linear fit (solid, black line) shows that, on average, subjects underestimate

\footnotetext{
${ }^{17}$ Our choice of the first night is arbitrary; analogous figures for other nights look strongly similar. Comparison of bedtime plans, self-reports and Fitbit readings suggests subjects frequently failed to correctly enter a.m. or p.m. For both planned and self-reported bedtimes, we assume reports in the range from 10 a.m. to 3 p.m. reflect this type of error.
} 
Figure 7: Planned and actual bedtimes, first night

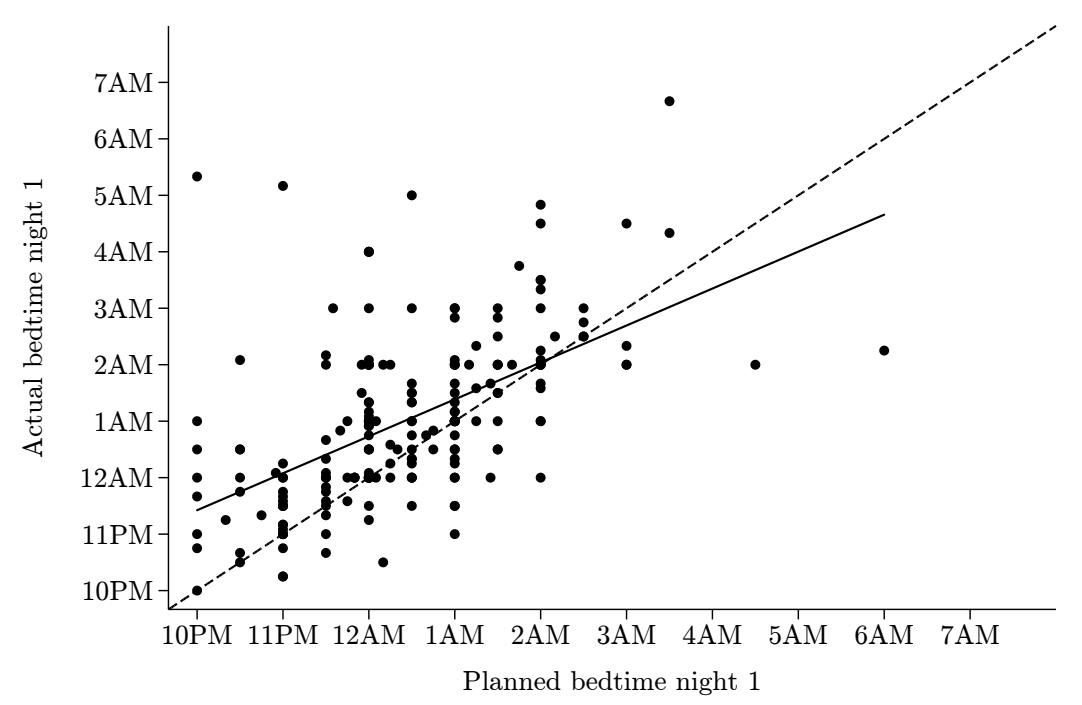

Notes: The figure shows planned bedtime ( $x$-axis) versus actual bedtime ( $y$ axis) for all observations on the first night of the study. Points above the 45 degree line (dashed), indicate that subjects went to bed later than their stated plan. A linear fit (solid, black line) shows that, on average, subjects underestimated their planned bedtime when going to bed earlier in the evening and overestimated later in the evening.

their bedtime earlier in the evening and tend to overestimate it later in the evening, though the overestimation is supported by relatively few observations.

Figure 7 uses a single night's planned and actual bedtime because we want to highlight three types of noise in the data. First, there is considerable round-number heaping in both planned and actual bedtimes. Planned bedtimes in particular are likely to fall on the hour or half hour. Second, 35 subjects report actual bedtime exactly equal to planned bedtime. Although these subjects might have gone to bed around the time that they planned, an exact match between plan and realization could reflect misreporting. Finally, some subjects report extreme bedtime plans and realizations. On this night, for instance, 9 subjects reported going to bed later than 4 a.m. Although extreme bedtime values are not necessarily in error, they could exert disproportionate influence on regression analysis.

Like task postponement, bedtime forecast error can be interpreted as a measure of procrastination. We therefore re-estimate Equation (4), but using forecast error rather than tasks put off. To reduce the influence of noise in the bedtime data 
Table 5: Effect of treatment on bedtime forecast error

\begin{tabular}{lcc}
\hline & $\begin{array}{c}(1) \\
\text { Discrete } \\
\text { forecast error } \\
\text { week 2 }\end{array}$ & $\begin{array}{c}(2) \\
\text { Discrete } \\
\text { forecast error } \\
\text { week 2 }\end{array}$ \\
\hline Treat & $-0.55^{*}$ & $-0.61^{* *}$ \\
& $(0.29)$ & $(0.30)$ \\
Forecast error (normalized) & & 0.63 \\
Forecast error (normalized) $\times$ Treat & & $(0.38)$ \\
& & $-0.79^{* *}$ \\
\hline Wk. 1 forecast error control & Yes & $(0.40)$ \\
Wave controls & Yes & Yes \\
Demographic controls & Yes & Yes \\
Observations & 202 & 202 \\
\hline
\end{tabular}

Notes: Subjects who do not go to sleep at all are excluded from the sample. Each column of the table shows results from a separate regression. All regressions contain the following controls: an indicator for gender, indicators for study wave, age, age squared, and an indicator for whether the subject was employed at the time of the study. In parentheses are heteroskedasticity-robust standard errors (White, 1980). Significance indicated by: ${ }^{* * *} \mathrm{p}<0.01,{ }^{*} \mathrm{p}<0.05,{ }^{*} \mathrm{p}<0.1$.

highlighted above, we employ a trichotomized measure of forecast error. We classify bedtime forecast error into one group if the subject underestimated her bedtime, a second group if her prediction exactly matched her actual bedtime, and a third group if she overestimated her bedtime. Table 5 shows results from estimating the effect of treatment on this trichotomized bedtime error variable, using an ordered logit. ${ }^{18}$

Although we prefer the results using tasks put off because completion of the tasks was incentivized, the results using bedtime forecast error are qualitatively similar. Bedtime may have the advantage of stronger external validity. On average, treated subjects reduced their forecast error. For subjects who had relatively higher error in week 1, treatment caused an even larger reduction in error during week 2 .

We also estimate simple regressions of bedtime, wake time, and sleep duration on a treatment indicator. Table 6 reports results. Treated agents delay bedtime by

\footnotetext{
${ }^{18}$ Subjects who do not go to sleep at all are excluded from the sample, as their forecast errors are not well defined. Most of these subjects report studying through the night. Assigning these subjects to the first group does not meaningfully change the estimates. Appendix Table 12 reports results without the adjustment of planned bedtimes between 10 a.m. and 3 p.m.. Estimates are strongly similar in both magnitude and statistical significance.
} 
Table 6: Effect of treatment on bedtime and sleep

\begin{tabular}{lccc}
\hline & $(1)$ & $(2)$ & $(3)$ \\
& Bedtime week 2 & Wake time week 2 & Sleep week 2 \\
\hline Treat & $19.3^{* *}$ & 1.05 & $-36.2^{* *}$ \\
Bedtime week 1 & $(9.19)$ & $(8.38)$ & $(14.6)$ \\
Wake time week 1 & $\left(0.63^{* * *}\right.$ & & \\
Sleep week 1 & & $0.71^{* * *}$ & \\
& & $(0.057)$ & $0.36^{* * *}$ \\
& & & $(0.081)$ \\
Wave controls & Yes & Yes & Yes \\
Demographic controls & Yes & Yes & Yes \\
Observations & 208 & 206 & 196 \\
\hline
\end{tabular}

Notes: Each column of the table shows results from a separate regression. All regressions contain the following controls: an indicator for gender, indicators for study wave, age, age squared, and an indicator for whether the subject was employed at the time of the study. In parentheses are heteroskedasticity-robust standard errors (White, 1980). Significance indicated by: ${ }^{* * *} \mathrm{p}<0.01,{ }^{* *} \mathrm{p}<0.05,{ }^{*} \mathrm{p}<0.1$.

about 20 minutes, but do not substantially adjust wake time. This pattern of results is similar to those found in Gibson and Shrader (in press). Going to bed later while holding wake time fixed leads to a decrease in sleep time. The estimated effect is larger than the bedtime and wake time changes suggest due to differences in sample and the inclusion of naps.

So far in this section we have been concerned largely with beliefs over time shocks. These beliefs are presumably costly to form and update. That agents engage in such costly forecasting suggests the underlying time shocks matter for welfare, and yet optimizing responses to such shocks are substantially understudied. Using time budget recall data, we are able to investigate the effect of an experimentally administered time shock on other time use choices. The randomly assigned shock that subjects face is the price at which they are offered commitment (i.e. the line of the price list which is implemented). Empirically, an increase in the price of commitment by one is associated with a subject needing to complete an additional two-thirds of a task. Each task took about 1.3 minutes for the median participant and 2.2 minutes for the mean participant in the study, so the treatment is equal to about 1 to 1.5 minutes of induced experimental time. This randomization allows for a series of tests on realized 
time use. While these are interesting reduced-form exercises, they are not theoretically founded and results should be interpreted cautiously. We estimate equations of the following form:

$$
\Delta \text { Time }_{i}=\alpha_{0}+\alpha_{1} \Delta \text { Time } \operatorname{Shock}_{i}+\mathbf{x}_{i}^{\prime} \xi_{4}+\varepsilon_{3, i}
$$

In the above equation $\Delta$ Time $_{i}$ is the change in time spent on a given activity between weeks 1 and 2, $\Delta$ Time Shock $k_{i}$ is the change in commitment price between the two weeks, $\varepsilon_{3, i}$ is the stochastic error term associated with this regression, and all other variables are the same as in Equation (4).

Table 7: Time use and commitment price

\begin{tabular}{lcccc}
\hline & Class & Exercising & Other & Sleeping \\
\hline Time Shock - diff. & -0.95 & 0.38 & $4.94^{* *}$ & -1.28 \\
& $(1.32)$ & $(0.54)$ & $(2.31)$ & $(1.45)$ \\
\hline Observations & 209 & 209 & 209 & 209 \\
\hline & & & & \\
& Socializing & Studying & TV & Working \\
\hline Time Shock - diff. & 1.45 & $-5.04^{* *}$ & $2.25^{*}$ & $-1.75^{*}$ \\
& $(1.95)$ & $(2.54)$ & $(1.22)$ & $(0.91)$ \\
\hline Observations & 209 & 209 & 209 & 209 \\
\hline
\end{tabular}

Notes: The table shows results from estimating equation 6 . Each column is a separate regression. Time use changes are in minutes. All regressions contain the following controls: an indicator for gender, indicators for study wave, age, age squared, and an indicator for whether the subject was employed at the time of the study. In parentheses are heteroskedasticity-robust standard errors (White, 1980). Significance indicated by: ${ }^{* * *} \mathrm{p}<0.01$, ** $\mathrm{p}<0.05$, * $\mathrm{p}<0.1$.

Table 7 reports the estimated effects of a marginal increase in commitment price on time use, measured in minutes per day. When commitment is more expensive, we find a statistically significant decrease in studying. We find statistically significant increases in other time and television; the latter result is consistent with TV being a time use luxury, as found in Aguiar et al. (2017). This is potentially consistent with present-biased preferences, as agents substitute toward immediately pleasurable uses and away from a time use with largely deferred payoffs. The estimates are also consistent with agents offsetting shocks in one time use with changes in other uses. 
While these changes in time allocation are small, they are responses to small changes in the (in-kind) price of commitment.

\section{Conclusion}

This paper models agents whose dynamic inconsistency potentially arises from two sources: discounting and beliefs. Agents with optimistic beliefs about future time shocks will exhibit dynamically-inconsistent choices over effort that are observationally equivalent to those driven by present bias. An informational intervention that tells agents about their past time inconsistency, however, will yield different behavior for these two biases. Optimistic agents will change effort allocations, but agents with present bias will not. Present biased agents should increase commitment demand, while optimistic agents will not necessarily do so.

We experimentally test these different predictions and find that both preferences and beliefs matter for time inconsistency. The results help explain puzzlingly low takeup of costly commitment and offer an alternative policy prescription to help overcome time inconsistent behavior - providing information on agents' own past choices.

The welfare effects of an informational treatment on behaviorally biased agents are unclear. To the extent that information pushes a naïvely present-biased decision maker towards sophistication, she will be better able to make plans that account for her present-biased future self. On the other hand, if optimistic beliefs are directly valuable to decision makers, giving them clear evidence their beliefs are biased could make them worse off. One avenue for future research is to identify situations in which subjects demand this information, and how it can be structured to improve decision making with minimal associated welfare losses. 


\section{References}

Acland, D. and M. R. Levy (2015). Naiveté, projection bias, and habit formation in gym attendance. Management Science 61(1), 146-160.

Aguiar, M., M. Bils, K. K. Charles, and E. Hurst (2017). Leisure luxuries and the labor supply of young men. NBER Working Paper No. 23552.

Andreoni, J. and C. Sprenger (2012a). Estimating time preferences from convex budgets. American Economic Review 102(7), 3333-56.

Andreoni, J. and C. Sprenger (2012b). Risk Preferences Are Not Time Preferences. American Economic Review 102(7), 3357-3376.

Ashraf, N., D. Karlan, and W. Yin (2006). Tying Odysseus to the Mast: Evidence from a Commitment Savings Product in the Philippines. Quarterly Journal of Economics 121(2), 635-672.

Augenblick, N., M. Niederle, and C. Sprenger (2015). Working over time: Dynamic inconsistency in real effort tasks. Quarterly Journal of Economics (2001), 10671115 .

Augenblick, N. and M. Rabin (In press). An experiment on time preference and misprediction in unpleasant tasks. Review of Economic Studies.

Barro, R. J. (1999). Ramsey meets laibson in the neoclassical growth model. The Quarterly Journal of Economics 114(4), 1125-1152.

Bénabou, R. and J. Tirole (2002). Self-confidence and personal motivation. Quarterly Journal of Economics 117(3), 871-915.

Börsch-Supan, A. H., T. Bucher-Koenen, M. D. Hurd, and S. Rohwedder (2018). Saving regret. Technical report, National Bureau of Economic Research.

Browning, M. and J. Tobacman (2015). Discounting and optimism equivalences.

Brunnermeier, M. K., F. Papakonstantinou, and J. A. Parker (2016). Optimal timeinconsistent beliefs: Misplanning, procrastination, and commitment. Management Science 63(5), 1318-1340. 
Brunnermeier, M. K. and J. A. Parker (2005). Optimal expectations. American Economic Review 95(4), 1092-1118.

Camerer, C. and D. Lovallo (1999). Overconfidence and excess entry: An experimental approach. American Economic Review 89(1), 306-318.

DellaVigna, S. and U. Malmendier (2006). Paying not to go to the gym. American Economic Review 96(3), 694-719.

Eil, D. and J. M. Rao (2011). The good news-bad news effect: asymmetric processing of objective information about yourself. American Economic Journal: Microeconomics 3(2), 114-38.

Falk, A., D. Huffman, and U. Sunde (2006). Self-confidence and search. IZA Working Paper No. 2525.

Frazis, H. and J. Stewart (2012). How to Think About Time-Use Data: What Inferences Can We Make About Long- and Short-Run Time Use from Time Diaries? Annals of economics and statistics 105/106, 231-245.

Frederick, S., G. Loewenstein, and T. O'donoghue (2002). Time discounting and time preference: A critical review. Journal of Economic Literature 40(2), 351-401.

Gabaix, X. (2014). A Sparsity-Based Model of Bounded Rationality. Quarterly Journal of Economics 129(4), 1661-1710.

Gabaix, X. and D. Laibson (2017). Myopia and Discounting. NBER Working Paper No. 23254, 37.

Gibson, M. and J. Shrader (2019). Time use and labor productivity: The returns to sleep. Review of Economics and Statistics.

Gill, D. and V. Prowse (2012). A structural analysis of disappointment aversion in a real effort competition. American Economic Review 102(1), 469-503.

Halevy, Y. (2008). Strotz meets allais: Diminishing impatience and the certainty effect. American Economic Review 98(3), 1145-62.

Hamermesh, D. S., H. Frazis, and J. Stewart (2005). Data watch: The American Time Use Survey. Journal of Economic Perspectives 19(1), 221-232. 
Kahneman, D. and A. Tversky (1982). Intuitive prediction: Biases and corrective procedures, pp. 414?421. Cambridge University Press.

Laibson, D. (1997). Golden eggs and hyperbolic discounting. Quarterly Journal of Economics 112(2), 443-478.

Laibson, D. (2015). Why Don't Present-Biased Agents Make Commitments? American Economic Review 105(5), 267-272.

Lam, T. C. and K. A. Small (2001). The value of time and reliability: measurement from a value pricing experiment. Transportation Research Part E: Logistics and Transportation Review 37(2-3), 231-251.

Larwood, L. and W. Whittaker (1977). Managerial myopia: Self-serving biases in organizational planning. Journal of Applied Psychology 62(2), 194.

Malmendier, U. and G. Tate (2005). CEO overconfidence and corporate investment. The Journal of Finance 60(6), 2661-2700.

Malmendier, U. and G. Tate (2008). Who makes acquisitions? CEO overconfidence and the market's reaction. Journal of Financial Economics 89(1), 20-43.

Mueller, A. I., J. Spinnewijn, and G. Topa (2018). Job Seekers' Perceptions and Employment Prospects: Heterogeneity, Duration Dependence and Bias. NBER Working Paper No. 25294, 70.

Niederle, M. and L. Vesterlund (2007). Do women shy away from competition? Do men compete too much? Quarterly Journal of Economics 122(3), 1067-1101.

O'Donoghue, T. and M. Rabin (1999). Doing It Now or Later. American Economic Review 89(1), 103-124.

Roy, M. M., N. J. Christenfeld, and C. R. McKenzie (2005). Underestimating the duration of future events: Memory incorrectly used or memory bias? Psychological Bulletin 131(5), 738.

Schilbach, F. Alcohol and self-control: A field experiment in india. American Economic Review. 
Small, K. A., C. Winston, and J. Yan (2005). Uncovering the distribution of motorists' preferences for travel time and reliability. Econometrica 73(4), 1367-1382.

Strotz, R. H. (1955). Myopia and inconsistency in dynamic utility maximization. Review of Economic Studies 23(3), 165.

Svenson, O. (1981). Are we all less risky and more skillful than our fellow drivers? Acta Psychologica 47(2), 143-148.

Taylor, S. E. and J. D. Brown (1988). Illusion and well-being: A social psychological perspective on mental health. Psychological Bulletin 103(2), 193.

Thaler, R. H. and S. Benartzi (2004). Save more tomorrow: Using behavioral economics to increase employee saving. Journal of political Economy 112(S1), S164S187.

Toussaert, S. (2018). Eliciting temptation and self-control through menu choices: A lab experiment. Econometrica 86(3), 859-889.

Tversky, A. and D. Kahneman (1992). Advances in prospect theory: Cumulative representation of uncertainty. Journal of Risk and Uncertainty 5(4), 297-323.

White, H. (1980). A heteroskedasticity-consistent covariance matrix estimator and a direct test for heteroskedasticity. Econometrica 48(4), 817-838. 


\section{Appendix for online publication}




\section{A Appendix figures and tables}

Figure 8: Commitment demand week in 2

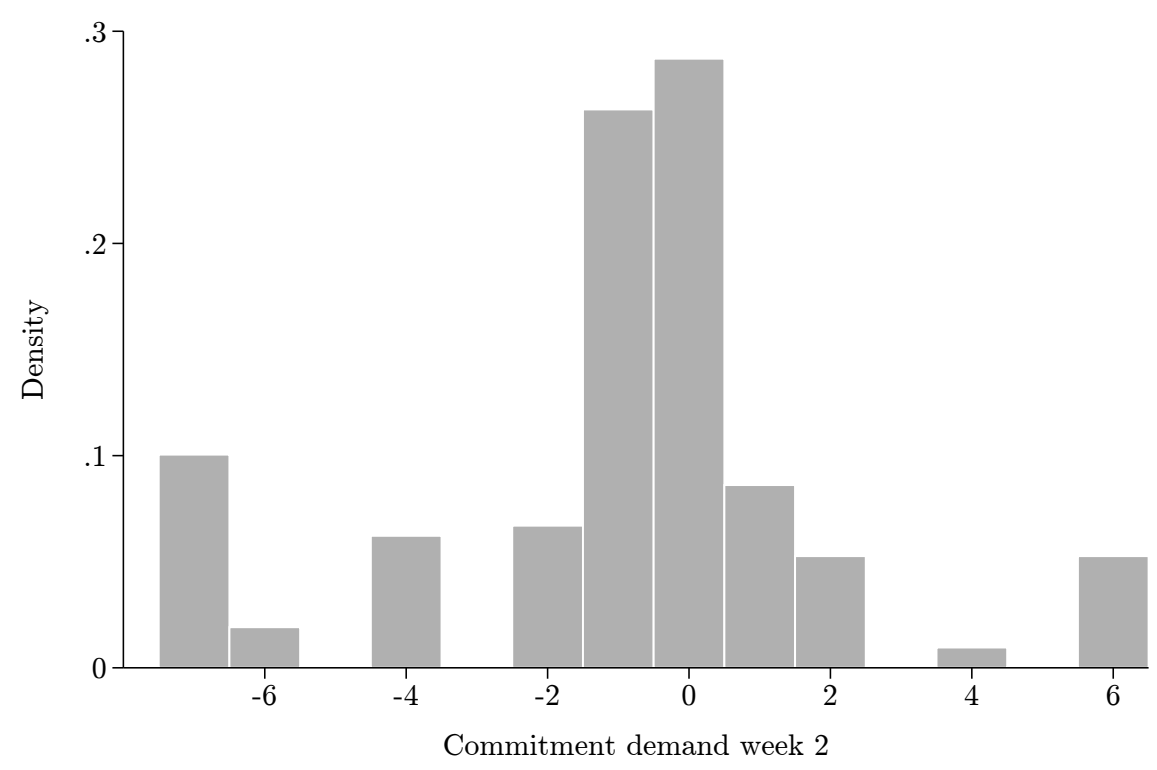

Notes: The figures show commitment demand for subjects in week 2, after treatment. The $x$-axis shows the price paid for commitment in terms of extra tasks. 
Table 8: Regression of study completion dummy on observables

\begin{tabular}{lc}
\hline & $(1)$ \\
& Finished study \\
\hline Treat & 0.052 \\
& $(0.053)$ \\
Age & 0.018 \\
& $(0.013)$ \\
GPA & 0.070 \\
& $(0.055)$ \\
Female (indicator) & 0.035 \\
& $(0.054)$ \\
Study wave & 0.024 \\
& $(0.023)$ \\
\hline Observations & 273 \\
\hline
\end{tabular}

Notes: Sample includes all subjects who completed our baseline survey instrument: 64 who did not complete the study and 209 who did. Estimates are from a regression of a study completion dummy on the listed variables. No other variables are included. In parentheses are heteroskedasticity-robust standard errors (White, 1980). Significance indicated by: *** $\mathrm{p}<0.01$, ** $\mathrm{p}<0.05$, * $\mathrm{p}<0.1$. 
Table 9: Effect of treatment on planned tasks

\begin{tabular}{lcccc}
\hline & $\begin{array}{c}(1) \\
\text { Morning tasks } \\
\text { week 2 }\end{array}$ & $\begin{array}{c}(2) \\
\text { Morning tasks } \\
\text { week 2 }\end{array}$ & $\begin{array}{c}(3) \\
\text { Evening tasks } \\
\text { week 2 }\end{array}$ & $\begin{array}{c}\text { Evening tasks } \\
\text { week } 2\end{array}$ \\
\hline Treat & -0.13 & -0.13 & -0.45 & -0.49 \\
Work put off week 1 & $(0.43)$ & $(0.44)$ & $(0.50)$ & $(0.52)$ \\
Treat $\times$ Work put off week 1 & 0.15 & 0.15 & -0.18 & -0.18 \\
& $(0.11)$ & $(0.11)$ & $(0.15)$ & $(0.15)$ \\
Wave controls & -0.29 & -0.30 & 0.13 & 0.13 \\
Demographic controls & $(0.22)$ & $(0.22)$ & $(0.27)$ & $(0.27)$ \\
Observations & Yes & Yes & Yes & Yes \\
\hline
\end{tabular}

Notes: The table shows results from estimating equation 4, but using planned postponement as the dependent variable. Each column shows the results of a separate regression. All regressions contain the following controls: an indicator for gender, indicators for study wave, age, age squared, GPA, GPA squared, and an indicator for whether the subject was employed at the time of the study. In parentheses are heteroskedasticity-robust standard errors (White, 1980). Significance indicated by: *** $\mathrm{p}<0.01,{ }^{* *} \mathrm{p}<0.05,{ }^{*} \mathrm{p}<0.1$. 
Table 10: Assessing experimenter demand using treatment message consistency

\begin{tabular}{|c|c|c|}
\hline & $\begin{array}{c}(1) \\
\text { Work put off } \\
\text { week } 2\end{array}$ & $\begin{array}{c}(2) \\
\text { Commitment } \\
\text { demand diff. }\end{array}$ \\
\hline Treat & $\begin{array}{c}0.57 \\
(0.49)\end{array}$ & $\begin{array}{l}-0.20 \\
(0.46)\end{array}$ \\
\hline Work put off week 1 & $\begin{array}{c}0.47^{* *} \\
(0.22)\end{array}$ & \\
\hline Treat $\times$ Work put off week 1 & $\begin{array}{c}-0.67^{* *} \\
(0.32)\end{array}$ & $\begin{array}{l}0.42^{*} \\
(0.21)\end{array}$ \\
\hline Bedtime error 1 & $\begin{array}{c}0.35 \\
(0.27)\end{array}$ & \\
\hline Treat $\times$ Bedtime error 1 & $\begin{array}{l}-0.14 \\
(0.34)\end{array}$ & $\begin{array}{c}0.11 \\
(0.18)\end{array}$ \\
\hline Work put off week $1 \times$ Bedtime error 1 & $\begin{array}{r}-0.079 \\
(0.11)\end{array}$ & \\
\hline Treat $\times$ Work put off week $1 \times$ Bedtime error 1 & $\begin{array}{c}0.28 \\
(0.40)\end{array}$ & $\begin{array}{c}0.052 \\
(0.20)\end{array}$ \\
\hline Wave controls & Yes & Yes \\
\hline Demographic controls & Yes & Yes \\
\hline Observations & 209 & 209 \\
\hline
\end{tabular}

Notes: The table shows results from estimating equations 4 and 5. "Bedtime error 1" is the bedtime prediction error reported (which was reported to treatment group subjects), divided by its own standard deviation. Controls and sample are the same as in Tables 3 and 4 . In parentheses are heteroskedasticity-robust standard errors (White, 1980). Significance indicated by: ${ }^{* * *} \mathrm{p}<0.01,{ }^{* *} \mathrm{p}<0.05,{ }^{*} \mathrm{p}<0.1$. 
Table 11: Treatment interactions with self-reported naïvete measures

\begin{tabular}{|c|c|c|c|}
\hline & $\begin{array}{c}(1) \\
\text { Change in } \\
\text { commitment } \\
\text { demand }\end{array}$ & $\begin{array}{c}(2) \\
\text { Change in } \\
\text { commitment } \\
\text { demand }\end{array}$ & $\begin{array}{c}(3) \\
\text { Work put } \\
\text { off } \\
\text { week } 2\end{array}$ \\
\hline Treat & $\begin{array}{l}-0.71 \\
(0.69)\end{array}$ & $\begin{array}{l}-0.69 \\
(0.59)\end{array}$ & $\begin{array}{c}0.13 \\
(0.49)\end{array}$ \\
\hline Treat $\times$ Procrastinate & $\begin{array}{c}0.77 \\
(0.67)\end{array}$ & & \\
\hline Treat $\times$ Work put off week 1 & $\begin{array}{c}0.79^{* * *} \\
(0.13)\end{array}$ & $\begin{array}{c}0.88^{* * *} \\
(0.29)\end{array}$ & $\begin{array}{l}-0.79^{*} \\
(0.41)\end{array}$ \\
\hline Work put off week 1 & & & $\begin{array}{c}0.44 \\
(0.28)\end{array}$ \\
\hline Treat $\times$ Work put off week $1 \times$ Procrastinate & $\begin{array}{c}-0.54^{* *} \\
(0.27)\end{array}$ & & \\
\hline Treat $\times$ Bedtime regret & & $\begin{array}{c}0.18 \\
(0.14)\end{array}$ & \\
\hline Treat $\times$ Work put off week $1 \times$ Bedtime regret & & $\begin{array}{l}-0.18^{*} \\
(0.095)\end{array}$ & \\
\hline Busy today & & & $\begin{array}{l}-0.11 \\
(0.56)\end{array}$ \\
\hline Treat $\times$ Busy today & & & $\begin{array}{c}0.36 \\
(0.76)\end{array}$ \\
\hline Work put off week 1 × Busy today & & & $\begin{array}{l}-0.17 \\
(0.32)\end{array}$ \\
\hline Treat $\times$ Work put off week $1 \times$ Busy today & & & $\begin{array}{c}0.56 \\
(0.46)\end{array}$ \\
\hline Wave controls & Yes & Yes & Yes \\
\hline Demographic controls & Yes & Yes & Yes \\
\hline Observations & 209 & 209 & 209 \\
\hline
\end{tabular}

Notes: The table shows results from estimating modified versions of equations 4 and 5 that include interactions with self-reported measures of procrastination and busyness. In parentheses are heteroskedasticityrobust standard errors (White, 1980). Significance indicated by: *** $\mathrm{p}<0.01,{ }^{* *} \mathrm{p}<0.05,{ }^{*} \mathrm{p}<0.1$. 
Table 12: Effect of treatment on bedtime forecast error, raw planned bedtimes

\begin{tabular}{lcc}
\hline & $\begin{array}{c}(1) \\
\text { Discrete } \\
\text { forecast error } \\
\text { week 2 }\end{array}$ & $\begin{array}{c}(2) \\
\text { Discrete } \\
\text { forecast error } \\
\text { week 2 }\end{array}$ \\
\hline Treat & $-0.61^{* *}$ & $-0.69^{* *}$ \\
& $(0.29)$ & $(0.31)$ \\
Forecast error (normalized) & & $1.11^{*}$ \\
Forecast error (normalized) $\times$ Treat & & $(0.57)$ \\
& & $-1.18^{* *}$ \\
\hline Wk. 1 forecast error control & & $(0.60)$ \\
Wave controls & Yes & Yes \\
Demographic controls & Yes & Yes \\
Observations & Yes & Yes \\
\hline
\end{tabular}

Notes: Forecast error based on raw self-reported planned bedtime, without adjusting planned bedtimes 10 a.m.-3 p.m. for likely a.m.-p.m. entry error. Each column of the table shows results from a separate regression. All regressions contain the following controls: an indicator for gender, indicators for study wave, age, age squared, and an indicator for whether the subject was employed at the time of the study. In parentheses are heteroskedasticity-robust standard errors (White, 1980). Significance indicated by: *** $\mathrm{p}<0.01$, ** $\mathrm{p}<0.05,{ }^{*} \mathrm{p}<0.1$. 
Table 13: Finite Mixture Model

\begin{tabular}{|c|c|c|c|c|}
\hline & Class 1 & Class 2 & Class 3 & Class 4 \\
\hline \multicolumn{5}{|l|}{$\begin{array}{c}\text { Work put off } \\
\text { week } 2\end{array}$} \\
\hline Treat & $\begin{array}{c}0.98 \\
(1.08)\end{array}$ & $\begin{array}{c}1.43 \\
(1.34)\end{array}$ & $\begin{array}{l}-0.08 \\
(0.55)\end{array}$ & $\begin{array}{l}-0.05 \\
(0.54)\end{array}$ \\
\hline Work put off week 1 & $\begin{array}{l}-0.00 \\
(0.03)\end{array}$ & $\begin{array}{c}0.44^{* * *} \\
(0.07)\end{array}$ & $\begin{array}{l}-0.05 \\
(0.05)\end{array}$ & $\begin{array}{c}1.04^{* * *} \\
(0.07)\end{array}$ \\
\hline Treat $\times$ Work put off week 1 & $\begin{array}{l}-0.14 \\
(0.12)\end{array}$ & $\begin{array}{c}-1.91^{* * *} \\
(0.21) \\
\end{array}$ & $\begin{array}{c}1.20^{* * *} \\
(0.16) \\
\end{array}$ & $\begin{array}{c}-1.98^{* * *} \\
(0.21) \\
\end{array}$ \\
\hline \multicolumn{5}{|l|}{$\begin{array}{c}\text { Change in } \\
\text { commitment } \\
\text { demand }\end{array}$} \\
\hline Treat & $\begin{array}{l}4.16^{* *} \\
(1.86)\end{array}$ & $\begin{array}{l}-0.71 \\
(0.66)\end{array}$ & $\begin{array}{c}0.22 \\
(0.85)\end{array}$ & $\begin{array}{l}-1.13 \\
(0.69)\end{array}$ \\
\hline Treat $\times$ Work put off week 1 & $\begin{array}{l}1.13^{* * *} \\
(0.15)\end{array}$ & $\begin{array}{c}-0.31^{* *} \\
(0.14)\end{array}$ & $\begin{array}{c}0.31 \\
(0.20) \\
\end{array}$ & $\begin{array}{l}-0.08 \\
(0.08) \\
\end{array}$ \\
\hline Latent Class Proportion & 0.097 & 0.074 & 0.418 & 0.411 \\
\hline
\end{tabular}

Notes: The table shows results from estimating equations 4 and 5 in a seemingly unrelated regression with Gaussian errors using maximum likelihood. Sets of coefficients are estimated for four classes. In parentheses are heteroskedasticity-robust standard errors (White, 1980). Significance indicated by: $* * * \mathrm{p}<0.01,{ }^{* *} \mathrm{p}<0.05$, $* \mathrm{p}<0.1$. 


\section{B Tables Without Multiple Switchers}

Table 14: Treatment-control balance without multiple switchers

\begin{tabular}{lccc}
\hline & Mean/(SD) & Mean/(SD) & Diff./(SE) \\
\hline Commitment demand week 1 & -1.03 & -0.24 & -0.79 \\
& $(3.20)$ & $(3.43)$ & $(0.52)$ \\
Commitment demand week 2 & -1.63 & -0.71 & $-0.92^{* *}$ \\
& $(2.79)$ & $(3.04)$ & $(0.46)$ \\
Work put off week 1 & -0.082 & -0.011 & -0.071 \\
& $(3.15)$ & $(1.92)$ & $(0.40)$ \\
Work put off week 2 & 0.22 & 0.56 & -0.34 \\
& $(2.74)$ & $(2.86)$ & $(0.44)$ \\
Bedtime difference from plan (minutes) & 42.9 & 44.6 & -1.74 \\
& $(67.7)$ & $(53.4)$ & $(9.46)$ \\
GPA & 3.26 & 3.32 & -0.062 \\
& $(0.47)$ & $(0.45)$ & $(0.072)$ \\
Female (indicator) & 0.58 & 0.68 & -0.11 \\
& $(0.50)$ & $(0.47)$ & $(0.076)$ \\
Study wave & 2.48 & 2.55 & -0.070 \\
& $(1.16)$ & $(1.11)$ & $(0.18)$ \\
\hline Observations & 73 & 91 & \\
\hline
\end{tabular}

Notes: The significance of the differences is assessed using a $t$-test. Significance indicated by: *** $\mathrm{p}<0.01,{ }^{* *} \mathrm{p}<0.05,{ }^{*} \mathrm{p}<0.1$. 
Table 15: Effect of treatment on work postponed without multiple switchers

\begin{tabular}{lccc}
\hline & $\begin{array}{c}(1) \\
\text { Work put off } \\
\text { week } 2\end{array}$ & $\begin{array}{c}(2) \\
\text { Work put off } \\
\text { week } 2\end{array}$ & $\begin{array}{c}(3) \\
\text { Work put off } \\
\text { week } 2\end{array}$ \\
\hline Treat & 0.32 & 0.40 & 0.26 \\
Work put off week 1 & $(0.43)$ & $(0.43)$ & $(0.44)$ \\
Treat $\times$ Work put off week 1 & $0.27^{*}$ & $0.28^{*}$ & $0.27^{*}$ \\
& $(0.15)$ & $(0.15)$ & $(0.15)$ \\
\hline Wave controls & $-0.40^{*}$ & $-0.43^{* *}$ & $-0.38^{*}$ \\
Demographic controls & $(0.21)$ & $(0.21)$ & $(0.21)$ \\
Additional controls & Yes & Yes & Yes \\
Adj. R ${ }^{2}$ & No & Yes & Yes \\
Observations & No & No & Yes \\
\hline
\end{tabular}

Notes: The table shows results from estimating equation 4 estimated on the sample that excludes multiple switchers. Each column shows the results of a separate regression. Controls are indicated at the bottom of each regression. Demographic controls are an indicator for gender, indicators for study wave, age, age squared, and an indicator for whether the subject was employed at the time of the study. Additional controls are GPA, GPA squared, and self-reported busyness during week 1 . In parentheses are heteroskedasticity-robust standard errors (White, 1980). Significance indicated by: ${ }^{* * *} \mathrm{p}<0.01,{ }^{* *} \mathrm{p}<0.05,{ }^{*} \mathrm{p}<0.1$. 
Table 16: Effect of treatment and task procrastination on commitment demand without multiple switchers

\begin{tabular}{lccc}
\hline & $\begin{array}{c}(1) \\
\text { Change in } \\
\text { commitment } \\
\text { demand }\end{array}$ & $\begin{array}{c}(2) \\
\text { Change in } \\
\text { commitment } \\
\text { demand }\end{array}$ & $\begin{array}{c}(3) \\
\text { Change in } \\
\text { commitment } \\
\text { demand }\end{array}$ \\
\hline Treat & 0.14 & 0.13 & -0.081 \\
Treat $\times$ Work put off week 1 & $(0.47)$ & $(0.47)$ & $(0.45)$ \\
& $0.47^{* * *}$ & $0.48^{* * *}$ & $0.47^{* *}$ \\
Wave controls & $(0.18)$ & $(0.18)$ & $(0.18)$ \\
Demographic controls & Yes & Yes & Yes \\
Additional controls & No & Yes & Yes \\
Adj. R R $^{2}$ & No & No & Yes \\
Observations & 0.03 & 0.02 & -0.0006 \\
\hline
\end{tabular}

Notes: The table shows results from estimating equation 5 estimated on the sample that excludes multiple switchers. Each column is a separate regression. Demographic controls are an indicator for gender, indicators for study wave, age, age squared, and an indicator for whether the subject was employed at the time of the study. Additional controls are GPA, GPA squared, and self-reported busyness in week 1 . In parentheses are heteroskedasticityrobust standard errors (White, 1980). Significance indicated by: ${ }^{* * *} \mathrm{p}<0.01,{ }^{* *} \mathrm{p}<0.05$, $* \mathrm{p}<0.1$. 
Table 17: Effect of treatment on planned tasks without multiple switchers

\begin{tabular}{lcccc}
\hline & $\begin{array}{c}(1) \\
\text { Morning tasks } \\
\text { week 2 }\end{array}$ & $\begin{array}{c}(2) \\
\text { Morning tasks } \\
\text { week 2 }\end{array}$ & $\begin{array}{c}(3) \\
\text { Evening tasks } \\
\text { week 2 }\end{array}$ & $\begin{array}{c}\text { Evening tasks } \\
\text { week 2 }\end{array}$ \\
\hline Treat & 0.13 & 0.15 & -0.18 & -0.24 \\
Work put off week 1 & $(0.50)$ & $(0.51)$ & $(0.59)$ & $(0.59)$ \\
Treat $\times$ Work put off week 1 & 0.16 & 0.16 & -0.11 & -0.11 \\
& $(0.11)$ & $(0.12)$ & $(0.16)$ & $(0.16)$ \\
& -0.26 & -0.26 & 0.14 & 0.17 \\
Wave controls & $(0.24)$ & $(0.25)$ & $(0.28)$ & $(0.29)$ \\
Demographic controls & Yes & Yes & Yes & Yes \\
Observations & No & Yes & No & Yes \\
\hline
\end{tabular}

Notes: The table shows results from estimating equation 4, but using planned postponement as the dependent variable, on the sample without multiple switchers. Each column shows the results of a separate regression. All regressions contain the following controls: an indicator for gender, indicators for study wave, age, age squared, GPA, GPA squared, and an indicator for whether the subject was employed at the time of the study. In parentheses are heteroskedasticity-robust standard errors (White, 1980). Significance indicated by: ${ }^{* * *} \mathrm{p}<0.01,{ }^{* *} \mathrm{p}<0.05,{ }^{*}$ $\mathrm{p}<0.1$.

Table 18: Effect of treatment on bedtime forecast error without multiple switchers

\begin{tabular}{lcc}
\hline & $\begin{array}{c}(1) \\
\text { Discrete } \\
\text { forecast error } \\
\text { week 2 }\end{array}$ & $\begin{array}{c}(2) \\
\text { Discrete } \\
\text { forecast error } \\
\text { week 2 }\end{array}$ \\
\hline Treat & $-0.69^{* *}$ & $-0.71^{*}$ \\
& $(0.35)$ & $(0.36)$ \\
Forecast error (normalized) & & -0.020 \\
Forecast error (normalized) $\times$ Treat & & $(0.32)$ \\
& & -0.38 \\
Wk. 1 forecast error control & Yes & $(0.35)$ \\
Wave controls & Yes & Yes \\
Demographic controls & Yes & Yes \\
Observations & 158 & 158 \\
\hline
\end{tabular}

Notes: Each column of the table shows results from a separate regression estimated on the sample that excludes multiple switchers. All regressions contain the following controls: an indicator for gender, indicators for study wave, age, age squared, and an indicator for whether the subject was employed at the time of the study. In parentheses are heteroskedasticity-robust standard errors (White, 1980). Significance indicated by: ${ }^{* * *} \mathrm{p}<0.01,{ }^{* *} \mathrm{p}<0.05,{ }^{*} \mathrm{p}<0.1$. 
Table 19: Effect of treatment on bedtime and sleep without multiple switchers

\begin{tabular}{lccc}
\hline & $(1)$ & $(2)$ & $(3)$ \\
& Bedtime week 2 & Wake time week 2 & Sleep week 2 \\
\hline Treat & $25.9^{* *}$ & 8.88 & -17.9 \\
Bedtime week 1 & $(10.1)$ & $(9.83)$ & $(16.1)$ \\
Wake time week 1 & $0.61^{* * *}$ & & \\
Sleep week 1 & $(0.074)$ & & \\
& & $0.71^{* * *}$ & \\
& & $(0.065)$ & $0.41^{* * *}$ \\
Wave controls & & & $(0.087)$ \\
Demographic controls & Yes & Yes & Yes \\
Observations & 164 & Yes & Yes \\
\hline
\end{tabular}

Notes: Each column of the table shows results from a separate regression, on the sample without multiple switchers. All regressions contain the following controls: an indicator for gender, indicators for study wave, age, age squared, and an indicator for whether the subject was employed at the time of the study. In parentheses are heteroskedasticity-robust standard errors (White, 1980). Significance indicated by: ${ }^{* * *} \mathrm{p}<0.01,{ }^{* *} \mathrm{p}<0.05,{ }^{*} \mathrm{p}<0.1$.

Table 20: Time use and commitment price without multiple switchers

\begin{tabular}{lcccc}
\hline & Class & Exercising & Other & Sleeping \\
\hline Time Shock - diff. & -0.89 & 0.53 & $4.49^{*}$ & -1.17 \\
& $(1.44)$ & $(0.57)$ & $(2.54)$ & $(1.52)$ \\
\hline Observations & 164 & 164 & 164 & 164 \\
\hline & & & & \\
& Socializing & Studying & TV & Working \\
\hline Time Shock - diff. & 2.46 & $-6.70^{* *}$ & $2.73^{* *}$ & -1.45 \\
& $(2.30)$ & $(2.68)$ & $(1.36)$ & $(0.91)$ \\
\hline Observations & 164 & 164 & 164 & 164 \\
\hline
\end{tabular}

Notes: The table shows results from estimating equation 6 , without multiple switchers. Each column is a separate regression. All regressions contain the following controls: an indicator for gender, indicators for study wave, age, age squared, and an indicator for whether the subject was employed at the time of the study. In parentheses are heteroskedasticity-robust standard errors (White, 1980). Significance indicated by: ${ }^{* * *} \mathrm{p}<0.01,{ }^{* *} \mathrm{p}<0.05,{ }^{*} \mathrm{p}<0.1$. 